\title{
Drought in the Southeastern United States: Causes, Variability over the Last Millennium, and the Potential for Future Hydroclimate Change*
}

\author{
RICHARD SEAGER \\ Lamont-Doherty Earth Observatory, Columbia University, Palisades, New York \\ AlEXANDrina TZANOVA \\ Columbia College, Columbia University, New York, New York \\ JENNIFER NAKAMURA \\ Lamont-Doherty Earth Observatory, Columbia University, Palisades, New York
}

(Manuscript received 16 June 2008, in final form 14 April 2009)

\begin{abstract}
An assessment of the nature and causes of drought in the southeastern United States is conducted as well as an assessment of model projections of anthropogenically forced hydroclimate change in this region. The study uses observations of precipitation, model simulations forced by historical SSTs from 1856 to 2007, tree-ring records of moisture availability over the last millennium, and climate change projections conducted for the Fourth Assessment Report of the Intergovernmental Panel on Climate Change. From the perspective of the historical record, the recent drought that began in winter 2005/06 was a typical event in terms of amplitude and duration. Observations and model simulations are used to show that dry winter half-years in the Southeast are weakly associated with La Niñas in the tropical Pacific but that this link varies over time and was possibly of opposite sign from about 1922 to 1950. Summer-season precipitation variability in the Southeast appears governed by purely internal atmospheric variability. As such, model simulations forced by historical SSTs have very limited skill in reproducing the instrumental record of Southeast precipitation variability and actual predictive skill is also presumably low. Tree-ring records show that the twentieth century has been moist from the perspective of the last millennium and free of long and severe droughts that were abundant in previous centuries. The tree-ring records show a 21-yr-long uninterrupted drought in the mid-sixteenth century, a long period of dry conditions in the early to mid-nineteenth century, and that the Southeast was also affected by some of the medieval megadroughts centered in western North America. Climate model projections predict that in the near term, future precipitation in the Southeast will increase but that evaporation will also increase. The median of the projections predicts a modest reduction in the atmospheric supply of water vapor to the region; however, the multimodel ensemble exhibits considerable variation, with a quarter to a third of the models projecting an increase in precipitation minus evaporation. The recent drought, forced by reduced precipitation and with reduced evaporation, has no signature of model-projected anthropogenic climate change.
\end{abstract}

\section{Introduction}

Perceptions of drought in North America normally focus on the arid and semiarid lands of the Great Plains

* Lamont-Doherty Earth Observatory Contribution Number 7294.

Corresponding author address: Dr. Richard Seager, LamontDoherty Earth Observatory, Columbia University, Rt. 9W, Palisades, NY 10964.

E-mail: seager@1deo.columbia.edu and Canadian Prairies, the interior West, the Southwest, and Mexico. It might be thought that this focus is a consequence of the dryness of these regions: precipitation reductions of equal magnitude will create larger effects on water resources in dry regions than in the more humid regions of the Northwest, Southeast, and Northeast. But there is more to it than that. Herweijer et al. (2007) used millennium-long tree-ring reconstructions of summer Palmer drought severity index (PDSI) over North America to show that, in the semiarid interior, decadal and longer time-scale variability explains a majority of the total variance compared to 
seasonal to interannual variability in the coastal regions. This spatial distribution closely matches the distribution of total precipitation and implies that the wet coastal regions, although experiencing large interannual variability, are not prone to the persistent multiyear droughts that plague the interior West and Great Plains.

Consistent with this, the great droughts of North America-including the Dust Bowl of the 1930s, the 1890s drought, the Southwest drought of the 1950s, and the post-1998 "turn of the century" drought—have all been centered in the central to western parts of the interior United States (Fye et al. 2003, 2004; Cook et al. 2004; McCabe et al. 2004; Schubert et al. 2004a,b; Seager et al. 2005b; Herweijer et al. 2006; Cook et al. 2007; Seager 2007). Furthermore, the multidecadal droughts that made up the medieval period of elevated aridity (Cook et al. 2004) were also centered in the interior West of North America (Herweijer et al. 2007). However, even though the eastern parts of the United States do not, in general, experience multiyear intense droughts, short periods of a year to a few years do occur when precipitation reductions place serious stresses on water resources. A striking example of such an event is the recent drought that began in winter 2005/06 in the southeastern United States. This drought extended at most two years-brief by Western standards-but has led to more than a billion dollars in crop losses and has placed massive strain on the water supply system of the affected states, pitting state against state and user against user, as all those affected attempt to avoid a drop off in available water (Manuel 2008).

At the root of the water supply problem in the Southeast is a growing population, driven in large part by in-migration, over the last few decades. For example, Georgia's population grew from 6478216 in 1990 to 8186453 in 2000 and an estimated 9544750 in 2007, according to U.S. census figures (available online at http:// www.census.gov) - that is an almost $50 \%$ increase in just $17 \mathrm{yr}$. Almost a quarter of total water use in Georgia, for example, is for public water supply (available online at http://ga.water.usgs.gov/projects/projectwateruse.html) and thus these population increases have placed notable stress on the available water resources.

The recent southeastern drought brings up several important questions that we attempt to answer here.

- How does the precipitation reduction that caused the recent drought compare with prior events in the instrumental record?

- What are the causes of drought in the Southeast? Is drought in this region caused by anomalies of sea surface temperatures (SSTs) (as in the West) or by random atmospheric variability?
- How well do climate models simulate hydroclimate variability in the Southeast? Is there potential for predicting hydroclimate variability in this region using predictions of SSTs?

- How do Southeastern droughts in the instrumental record compare to droughts over the last millennium inferred from tree-ring records? Have worse droughts occurred in more distant centuries?

- Is the recent drought in any way linked to anthropogenic climate change, and how is hydroclimate in the Southeast projected to change in the coming years to decades?

We will attempt to answer these questions using station and satellite measurements of precipitation in the region, observations of SST and sea level pressure (SLP), atmospheric model simulations of the 1856-2007 period forced by observed SSTs, atmospheric reanalyses and coupled atmosphere-ocean simulations of twentieth-century climate, and projections of current-century climate together with the Intergovernmental Panel on Climate Change Fourth Assessment Report (IPCC AR4). Examining such disparate data and model simulations necessarily requires a certain disjuncture in the metrics for drought and in the methods used. Analysis of the modern period will focus on the relation of drought to patterns of SST variability as a means of examining causes and predictability. We do not have SST records for the preinstrumental period, and the analysis will be more descriptive in nature. In addition, although variability continues in model projections of future hydroclimate change, there is also a trend toward increases in both precipitation and evaporation over the Southeast and that will be focused upon in this paper.

The tree-ring data used are reconstructions of the PDSI (Palmer 1965), but we choose not to convert the instrumental and model data to PDSI. PDSI has wellknown problems (Alley 1984; Karl 1986; van der Schrier et al. 2006), but we are particularly concerned by whether its simple computation of evapotranspiration is reliable as climate change increases evaporative demand but not necessarily the net surface radiation that provides the energy for evapotranspiration (Burke et al. 2006). Alterations to the PDSI that specify the net radiation yield more reasonable results within models, but they cannot be widely applied to observations because of the lack of radiation data (Burke et al. 2006). In this situation a uniform approach to current, past, and future hydroclimate variability and change is not possible. Hence, although we have no choice but to examine PDSI reconstructions in regard to the tree-ring data, for the instrumental period and the future our analysis focuses on precipitation and therefore on meteorological drought 
(AMS Council 1997; Heim 2002). Precipitation data is readily available and unambiguous, and droughts always involve reductions in precipitation (AMS Council 1997). Further, a focus on precipitation data allows us to make extensive use of satellite data with global coverage to examine the large-scale atmosphere-ocean context of drought in the Southeast. In a study of U.S. hydroclimate, Karnauskas et al. (2008) showed that at the regional scale, instrumental PDSI and precipitation track closely and "most differences are minor"; however, they also point out that PDSI can be notably affected by evaporation, which we accept. Although not resorting to PDSI, we will show that increased evapotranspiration is an important component of future projected climate change.

We will conclude that the recent drought was quite typical of historical droughts, that winter drought in the Southeast is weakly linked to a cold tropical Pacific Ocean, that summer drought is caused largely by internal atmospheric variability and, therefore, that there is limited predictability of extended droughts. We will also show that earlier centuries had droughts as severe as the recent one but which extended for as long as a decade or more. It will also be shown that the recent drought is unlikely to have been influenced by anthropogenic climate change but that the latter will lead to increased precipitation and also increased evapotranspiration with the potential for reduced soil moisture and river flow that would place further stress on regional water resources.

\section{Data and models}

\section{a. Observational data, reanalyses, and proxy reconstructions}

The precipitation data used here is the U.S. Climate Division data that extends from 1895 to the present. This consists of station data that have been binned into monthly values for each climate division. The climate divisions vary in size across the nation and are not of regular shape; however, in the Southeast they are typically about a degree in longitude and latitude. We also use the 1979 to present estimate of precipitation derived from gauges and satellites from the Global Precipitation Climatology Project (GPCP; Huffman et al. 1997). For SST we use the same data used to force the atmosphere model, as described below. This data consists of the Kaplan et al. (1998) data within the tropical Pacific (between $20^{\circ} \mathrm{N}$ and $20^{\circ} \mathrm{S}$ ) and the Hadley Centre data from Rayner et al. (2003) outside of the tropical Pacific. The Hadley data begin in 1871, whereas the Kaplan data begin in 1856 . Therefore, for $1856-70$ outside of the tropical Pacific, we use Kaplan data where available and climatological SST in places where the Kaplan dataset does not report an actual value. This method provides for a continuous record of tropical Pacific SSTs from a single dataset for the entire 1856-2007 period. For sea level pressure, we use the Hadley Centre data of Allan and Ansell (2006). For limited purposes we also use the National Centers for Environmental PredictionNational Center for Atmospheric Research (NCEPNCAR) reanalysis dataset (Kistler et al. 2001) and results from the Variable Infiltration Capacity (VIC) surface hydrology model forced by meteorological observations, as described by Liang et al. (1994) and Andreadis and Lettenmaier (2006). ${ }^{1}$

For a long-term perspective, we use an updated version (v2a; E. R. Cook, 2007 personal communication; available online at http://ingrid.ldgo.columbia.edu/expert/ home/.jennie/.PDSI/.NADAv2a/pdsi/) of the North American Drought Atlas (NADA) of Cook and Krusic (2004). This is a gridded dataset of summer-season PDSI constructed from tree-ring records across Canada, the United States, and northern Mexico. The update uses more tree-ring records than in the initial release but uses the same statistical methods. The NADA data are described in Cook et al. $(2004,2007)$. Here we analyze the period from A.D. 1000 to 2006.

\section{b. Atmospheric simulations forced by observed historical SSTS}

The atmosphere model used here is the NCAR Community Climate Model, version 3 (CCM3) run at T42 resolution with 18 vertical levels (Kiehl et al. 1998). The simulations used here are updates to September 2007 of large ensembles of the post- 1856 period that we have used extensively in previous studies of medieval-, nineteenth-, twentieth-, and current-century North American droughts (Seager et al. 2005b; Herweijer et al. 2006; Cook et al. 2007; Seager 2007; Seager et al. 2008b,a, 2009). The model simulations variously impose SST forcing globally or in individual ocean basins, a methodology introduced by Lau and Nath (1994), are as follows:

1. A 16-member ensemble from 1856 to 2007, each with different initial conditions, with global SST forcing.

\footnotetext{
${ }^{1}$ The VIC model is a hydrologic model that solves for both water and energy balances and includes subgrid-scale variations in soil moisture capacity, precipitation, vegetation, and topography. It includes a number of vegetation classes and has a detailed calculation of evapotranspiration that depends on vegetation characteristics. The model also includes a detailed treatment of snow, vertical exchanges at the surface and between layers, and also horizontal base flow in the bottom of the soil layers.
} 
This is the Global Ocean Global Atmosphere (GOGA) ensemble.

2. A 16-member ensemble from 1856 to 2007 with tropical Pacific $\left(20^{\circ} \mathrm{S}-20^{\circ} \mathrm{N}\right)$ SSTs specified and SSTs elsewhere computed using a two-layer ocean model in which the top layer is the mixed layer and has a specified seasonally varying depth (derived from observations) and exchanges heat and mass with the lower layer. Neglected ocean heat transport is accounted for by specified " $q$-fluxes" in each layer such that the climatological model temperatures in the two layers remain close to those observed. Details can be found in Seager et al. (2005b). This is the Pacific Ocean Global Atmosphere-Mixed Layer (POGA-ML) ensemble.

3. A 16-member ensemble from 1856 to 2007 with tropical Pacific $\left(20^{\circ} \mathrm{S}-20^{\circ} \mathrm{N}\right)$ SSTs specified as for POGA-ML but with climatological SSTs outside of this region. This is the POGA ensemble.

4. An 8-member ensemble from 1856 to 2007 with tropical Atlantic $\left(30^{\circ} \mathrm{S}-30^{\circ} \mathrm{N}\right) \mathrm{SSTs}$ specified and climatological SSTs elsewhere. This is the tropical Atlantic Global Atmosphere (TAGA) ensemble.

The SST forcing is the mixed Kaplan-Hadley dataset as described above. The ensemble members begin with different atmospheric initial conditions on 1 January 1856. Here we primarily focus on the ensemble mean of the model simulations which, for a large enough ensemble, isolates the component common to all ensemble members-that is, the part forced by the underlying SSTs-by averaging over the weather variability that is uncorrelated between the ensemble members. The component that is SST-forced is of particular interest because it is potentially predictable on the time scale of predictability of SST.

To verify that the model simulations are not unique, we also briefly examined the history of precipitation in the Southeast as modeled by five other atmosphere GCMs forced by observed SSTs, although none extend back before the middle of the last century.

\section{c. Simulations and projections of forced climate change}

To assess whether the recent drought was in anyway related to anthropogenic climate change, and to assess how hydroclimate is projected to change in the future in the Southeast, we use results from 24 models participating in the IPCC AR4 process (Houghton et al. 2007). We analyze the simulations of the twentieth century forced by known and estimated changes in trace gases, solar irradiance and, in some cases, volcanism and landuse change as well as the projections of current-century climate change generated with the Special Report on
Emissions Scenarios (SRES) A1B "middle of the road" emissions scenario that has $\mathrm{CO}_{2}$ emissions slightly decreasing after midcentury and $\mathrm{CO}_{2}$ concentrations increasing to $680 \mathrm{ppm}$ by 2100 .

\section{The recent drought in the perspective of the historical record of hydroclimate variations in the Southeast}

\section{a. Characterizing the recent drought}

Figure 1 shows maps of the observed precipitation anomaly for the half-years from November 2005-April 2006 through May-October 2007. The left column shows results from the climate division station data and uses climatology from 1895 to present. The right column uses the combined satellite-gauge data from GPCP relative to the shorter 1979-present climatology. GPCP data are plotted to see the large-scale patterns, including over the tropical Pacific Ocean, in which the Southeast precipitation anomaly is embedded.

The recent drought began in winter 2005/06 and was part of a drying across the southern United States that stretched from Arizona to the Atlantic Ocean. After that, dry conditions persisted in the western United States and in the Southeast through October 2007. The GPCP data indicate that the Southeast drought was associated with varying patterns of precipitation anomalies across the Pacific-North America sector. During November 2005-April 2006 and May-October 2007, there was reduced precipitation in the Pacific intertropical convergence zone (ITCZ) indicative of La Niña-like conditions, whereas in the two intervening years, even as dry conditions persisted in the Southeast, ITCZ precipitation was above normal, consistent with El Niño conditions. These changes in the tropical Pacific precipitation are consistent with SST anomalies there (not shown). Patterns of Atlantic Ocean precipitation also varied throughout the duration of the drought. It is immediately clear that the recent drought was not consistently and closely tied to tropical SST anomalies and the associated patterns of tropical precipitation anomalies.

Although the exact area of the Southeast that was affected by reduced precipitation in the last few years varied, an area average of land within $30^{\circ}-38^{\circ} \mathrm{N}, 92^{\circ}-$ $75^{\circ} \mathrm{W}$ will encompass the main areas. Figure 2 shows the time series of precipitation averaged over this area, according to the climate division data, for the period from 1895 to October 2007. The data have been averaged into November-April and May-October half-years. The recent drought is clear in the time series, but its precipitation reduction does not exceed earlier droughts, including one as recently as 1998-2002. 
Nov 2005 - Apr 2006
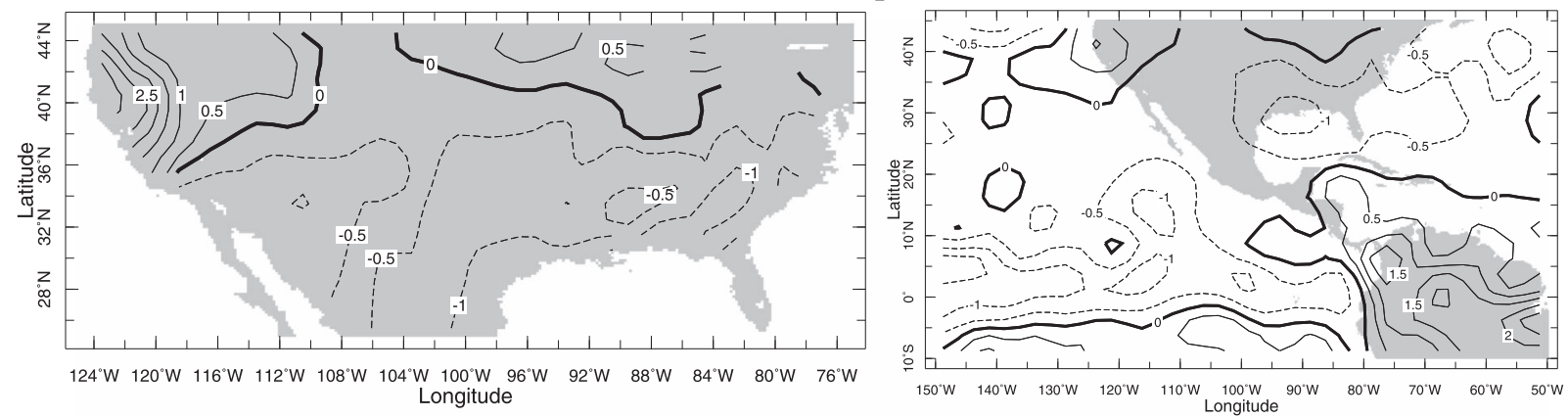

May 2006 - Oct 2006
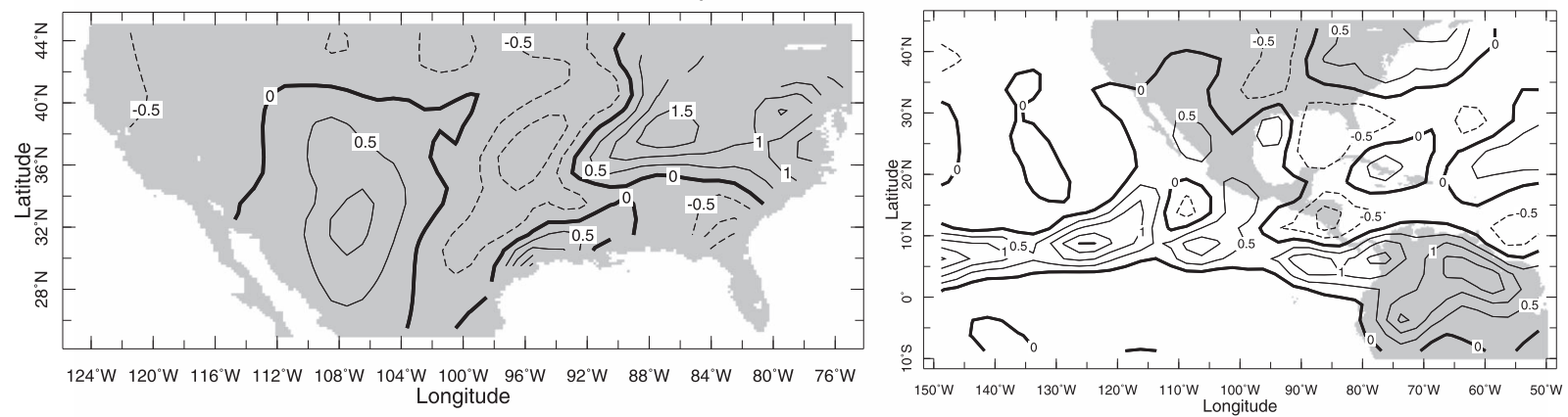

Nov 2006 - Apr 2007
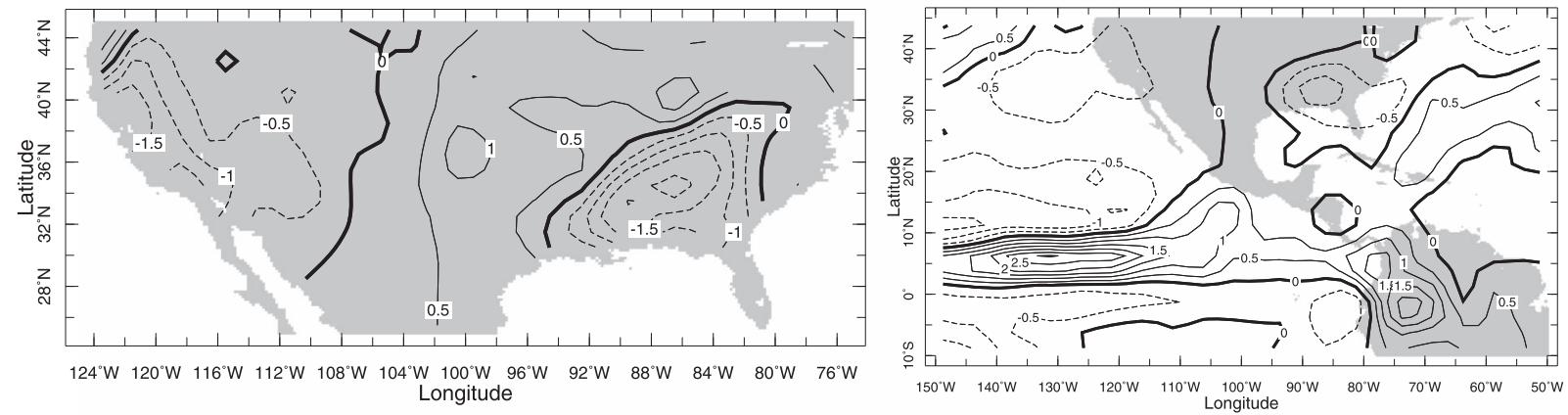

May 2007 - Oct 2007

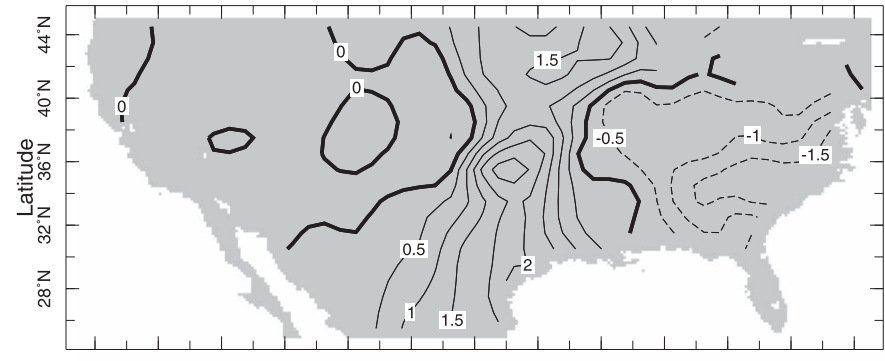

$124^{\circ} \mathrm{W} \quad 120^{\circ} \mathrm{W} \quad 116^{\circ} \mathrm{W} \quad 112^{\circ} \mathrm{W} \quad 108^{\circ} \mathrm{W} \quad 104^{\circ} \mathrm{W} \quad 100^{\circ} \mathrm{W} \quad 96^{\circ} \mathrm{W} \quad 92^{\circ} \mathrm{W} \quad 88^{\circ} \mathrm{W} \quad 84^{\circ} \mathrm{W} \quad 80^{\circ} \mathrm{W} \quad 76^{\circ} \mathrm{W}$ Longitude

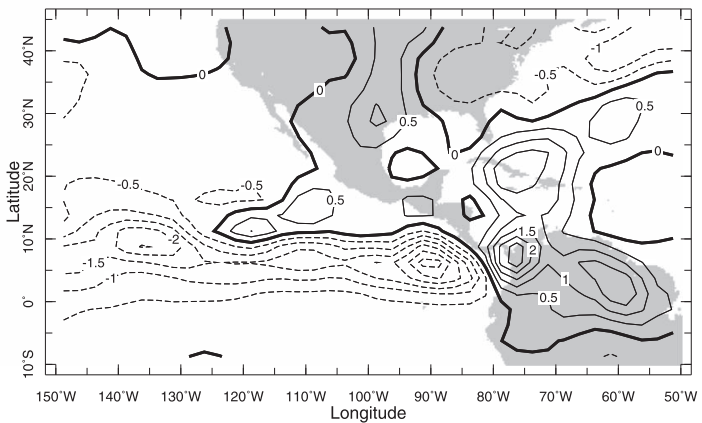

FIG. 1. The precipitation anomaly $\left(\mathrm{mm} \mathrm{day}^{-1}\right)$ for winter and summer half-years from fall 2005 to fall 2007 as derived from (left) climate division station data and (right) GPCP satellite-gauge data. The climate division data are relative to a January 1895-October 2007 climatology, and the GPCP data are relative to a January 1979-March 2008 climatology. 


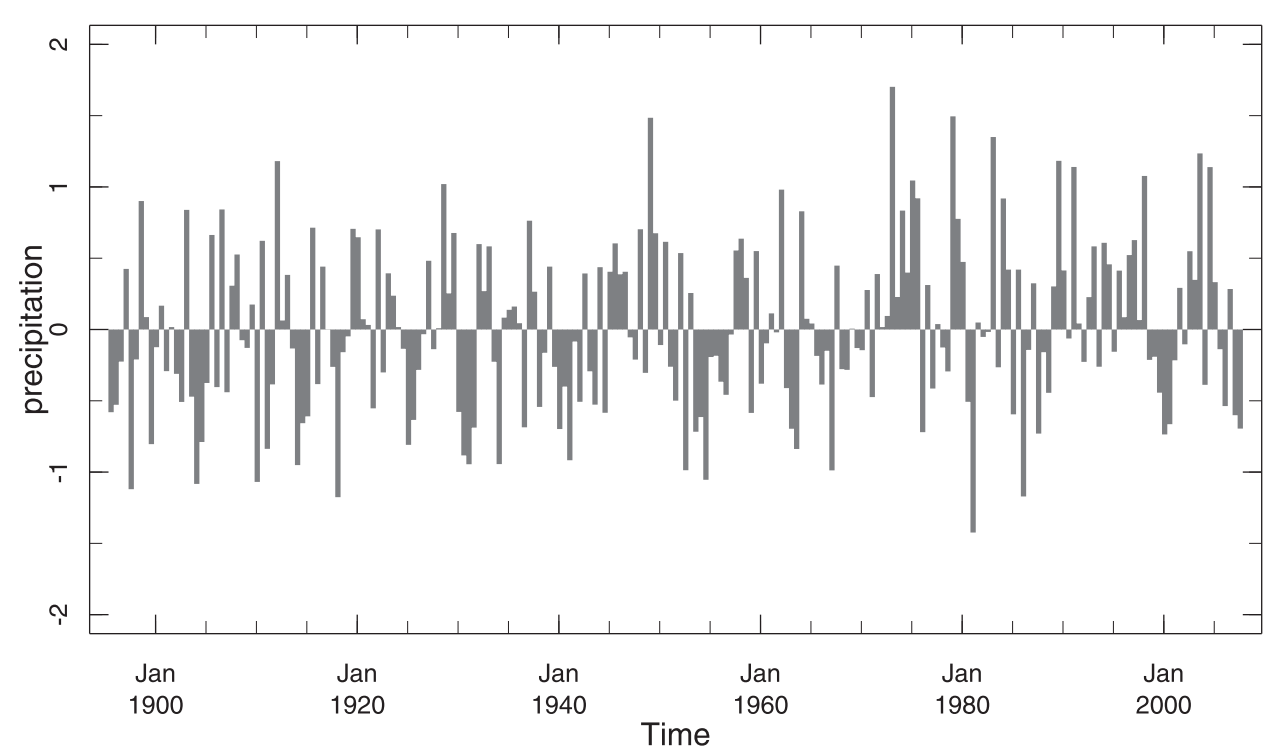

FIG. 2. The area-averaged $\left(30^{\circ}-38^{\circ} \mathrm{N}, 92^{\circ}-75^{\circ} \mathrm{W}\right)$ precipitation anomalies $\left(\mathrm{mm} \mathrm{day}^{-1}\right)$ for winter and summer half-years from 1895 to fall 2007 as derived from climate division station data. Values are plotted for November-April and May-October half-years and are relative to the 1895-2007 climatology.

\section{b. Association of Southeast precipitation variations with patterns of SST and sea level pressure variability}

An association between El Niño events and wet winters in the Southeast was noted by Ropelewski and Halpert (1987, 1989, 1996), Wu et al. (2005), Tootle and Piechota (2006), Cocke et al. (2007), and Kurtzman and Scanlon (2007). This relationship, however, does not appear to be stable in time. A time series of the correlation coefficient between winter half-year Southeast precipitation and the Niño-3.4 SST index (SST averaged over $5^{\circ} \mathrm{S}-5^{\circ} \mathrm{N}, 170^{\circ}-120^{\circ} \mathrm{W}$ ), evaluated in $20-$ and $30-\mathrm{yr}$ running windows, shows a high, positive correlation after about 1950 and before about 1922 but a weak negative correlation between these periods. Computing correlation coefficients between two time series using running windows is problematic (see Gershunov et al. 2001), which is why we do not show the running correlation plot here), and conclusions that draw on such statistics require independent backup to be credible.

Guided by that suggestive result, to look further into the relationship between winter half-year precipitation variability in the Southeast and global climate variations, we have correlated the time series of precipitation variations in Fig. 2 with SST and SLP variations for three time windows: 1895-1921, 1922-50, and 1951-2004. The ending year of 2004 matches with the ending year of the Hadley Centre SLP data. As shown (Fig. 3), during the winter half year of the early and late periods, wet conditions in the Southeast are associated with a prom- inent warm SST anomaly-an El Niño-in the tropical Pacific Ocean, but this is not so during the period in between. The associated SLP patterns show, for the early and late periods, anomalously low pressure over the anomalously warm eastern equatorial Pacific and anomalously high SLP over the western equatorial Pacific Ocean, indicative of a weaker Walker circulation. During these periods, there is high pressure over the subtropical North Pacific and low pressure over the subpolar North Pacific, again consistent with El Niño conditions. During the intervening period of 1922-50, the SLP pattern shows strong anomalous high pressure over the North Pacific and no evidence of an altered Walker circulation, consistent with the absence of a tropical Pacific SST anomaly.

These combined results suggest that the winter halfyear relationship of Southeast precipitation to global circulation and SSTs varied during the twentieth century, as noted before by Cole and Cook (1998). This is given further support by the regressions and correlations of Hadley Centre SLP data on the Niño-3.4 SST time series (Fig. 4). During the early and late periods, a classic ENSO-driven SLP pattern is seen with a strong Aleutian low and only weak SLP anomalies over the Atlantic Ocean. In contrast, during the $1922-50$ period, in addition to the deep Aleutian low, a deep low-pressure anomaly occurs over the Atlantic Ocean during El Niño winters with northerly flow over the Southeast.

It is possible that the Pacific decadal oscillation (PDO) plays a role in the variation over time of the global linkages of Southeast precipitation. The PDO 
a) 1895-1921

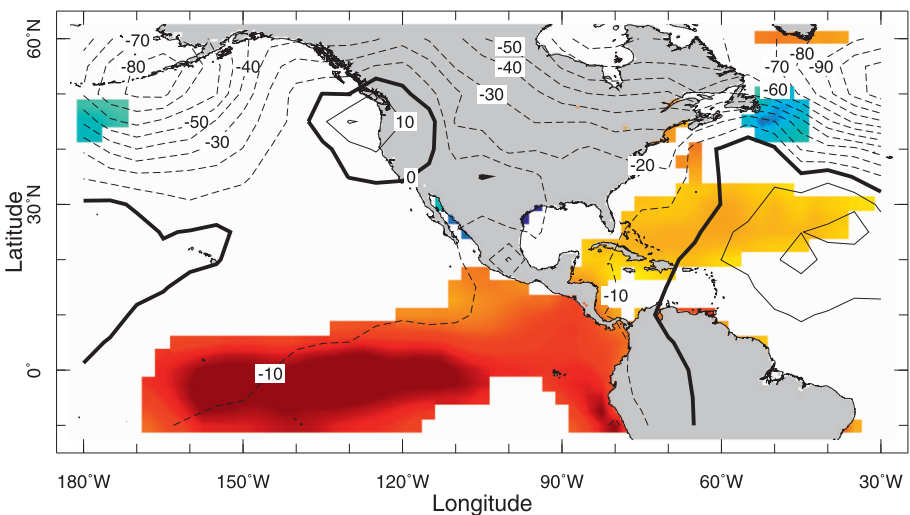

b) $\quad 1922-1950$

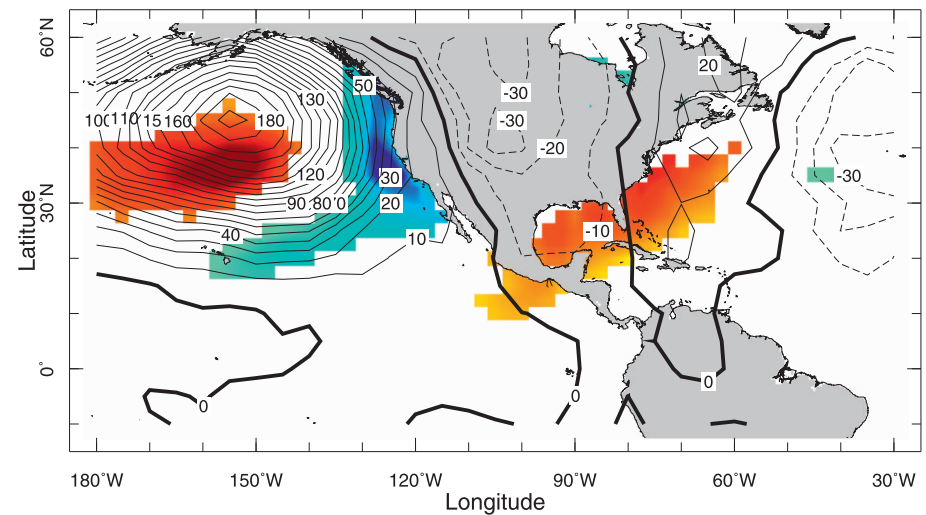

c) 1951-2004
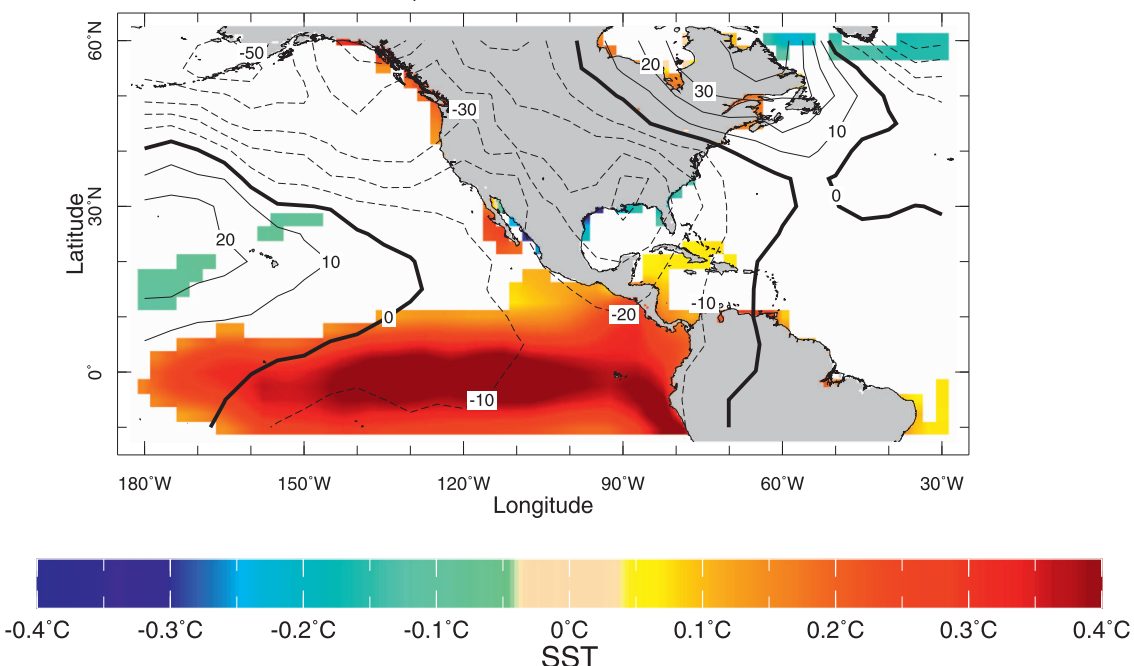

FIG. 3. The regression of the climate division area-averaged Southeast precipitation in November through April on the observed SST (colors, ${ }^{\circ} \mathrm{C}$ ) and SLP (contours, Pa). SST values are only plotted where they are statistically significant at the $5 \%$ level. Results are shown for three periods: 1895-1921, 1922-50, and 1951-2004. 
(a) $1895-1921$

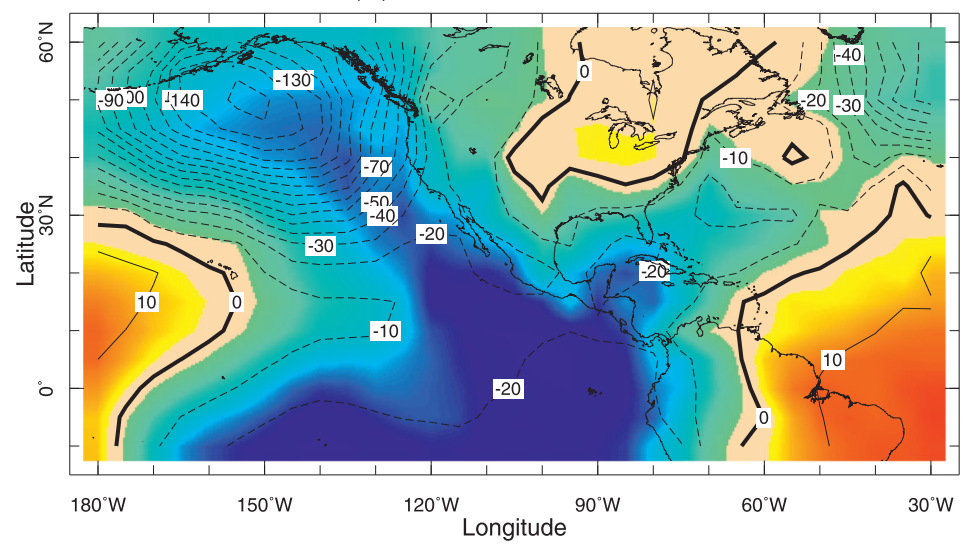

(b) $1922-1950$

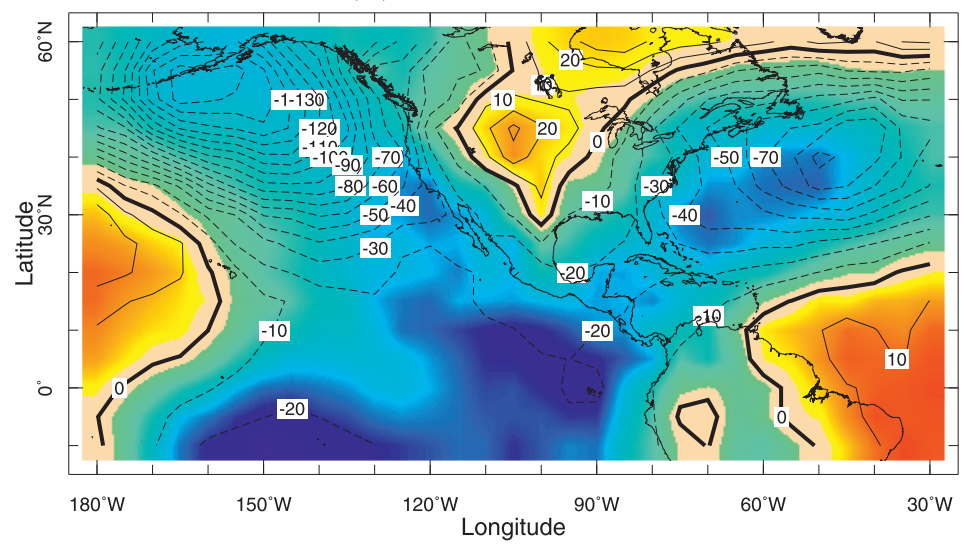

(c) 1951-2004
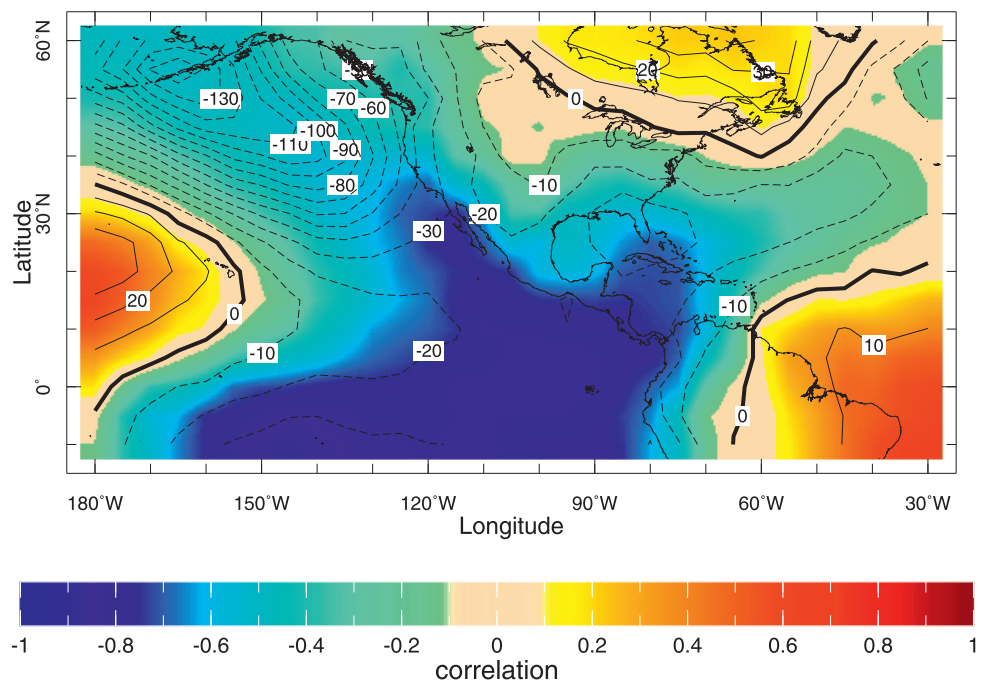

FIG. 4. The regression (contours) and correlation (color) of the Hadley Centre SLP data on the time series of Niño-3.4 SST index for three periods: 1895-1921, 1922-50, and 1951-2004. Units for the regression are Pascals per standard deviation of Niño-3.4. Correlation coefficients of 0.37 (0.49) and 0.27 (0.35) would be significant at the $5 \%(1 \%)$ levels for the first two periods and the final period, respectively, according to a Student's $t$ test. 
was defined by Mantua et al. (1997) as the first mode in an empirical orthogonal function/principal component analysis of Pacific SST north of $20^{\circ} \mathrm{N}$. Between 1922 and 1950, the PDO was primarily positive. The ENSOassociated Atlantic SLP signal during this period is stronger than before or after this period, which is consistent with the PDO "modulation of ENSO teleconnections" discussed by Gershunov and Barnett (1998). Typically El Niño winters cause anomalously wet conditions across the Southeast (Ropelewski and Halpert 1986; Seager et al. 2005a). When climate division precipitation is regressed on the Niño-3.4 SST index, this pattern of overall wetting of the Southeast is reproduced for the pre-1922 and post-1950 periods (not shown). However, for 1922-50 the boundary between wet conditions over the Southeast during El Niño and drier conditions to the north shifts southward into the middle of our Southeast region (not shown). This is potentially consistent with the northerly flow indicated by the SLP regressions on Niño-3.4 for this period (Fig. 4b).

This temporal variability in the ENSO teleconnection, possibly related to lower-frequency Pacific climate variability, may disrupt the tropical Pacific-Southeast precipitation connection during the $1922-50$ period. Whether or not this is so, Southeast precipitation variability during this period appears to be controlled by internal atmospheric variability. Indeed, the SST and SLP regression patterns shown in Fig. 3b frequently appear in the extratropically coupled (POGA-ML) model simulations to be discussed later when internal atmospheric variability is isolated by examining departures of ensemble members from the tropical Pacific SST-forced ensemble mean (not shown).

In contrast to the situation during the winter halfyear, summer half-year precipitation variability in the Southeast is not strongly associated with tropical Pacific or other SST anomalies at any time since 1895 (Fig. 5). Instead, both the SST and SLP correlations indicate a regionally localized, but temporally variable, association. In general, wet summers in the Southeast are associated with southerly flow anomalies into the region, which presumably brings ascending moist air. The pattern of low-level flow implied by the SLP pattern is consistent with the observed SST anomalies (e.g., anomalous northerly flow over the ocean causing cooling) but these are generally not statistically significant and not seen in Fig. 5. These results are indicative of internal atmospheric variability generating Southeast precipitation variability in the summer half-year and forcing the SST anomalies. This suggests that summer half-year precipitation variability in the Southeast arises from internal atmosphere processes and is essentially unpredictable.

\section{c. Southeast precipitation-global SST relationships in ensembles of SST-forced atmospheric model simulations}

The observations suggest that during some periods, winter half-year precipitation in the Southeast is closely tied to tropical Pacific SST anomalies but, during other periods, it is not. Any hope for predictability of Southeast precipitation on the seasonal to interannual time scale will require as a first step that the winter link to tropical Pacific SSTs, and its temporal variation, be reproduced in models forced by observed SSTs.

The ensemble mean of the GOGA simulations shows a strong correlation between winter half-year precipitation variations over the Southeast and tropical Pacific SST anomalies for the entire period of the simulations and does not show the 1922-50 observed reversal in correlation. (Individual ensemble members do show time-varying correlations between Niño-3.4 and Southeast precipitation but not with the same temporal behavior. These results could be indicative of a failure of the model to correctly respond to aspects of the observed SST fields but further investigation is beyond the scope of this paper.) Figure 6 shows the correlation and regression of GOGA surface temperature (which, over the ocean, is the observed global SST that was used to force the atmosphere model) and ensemble mean SLP on the ensemble mean GOGA precipitation anomaly for the Southeast $\left(30^{\circ}-38^{\circ} \mathrm{N}, 92^{\circ}-75^{\circ} \mathrm{W}\right.$, land areas only) for the entire 1856-2007 period. In the model ensemble mean wet winter half-years in the Southeast are clearly associated with El Niño conditions. This is emphasized by the fact that the same relation to SST and SLP is obtained when the analysis is conducted with the POGAML model, which has only tropical Pacific SST forcing (Fig. 7). The similarity of the GOGA and POGA-ML results indicates that the model, when forced with global SST anomalies, picked the tropical Pacific anomalies out as having the strongest link to the Southeast. The modeled patterns of SLP and SST associated with wet winters in the Southeast are quite similar to those derived from observations for the pre-1922 and post-1950 periods (Figs. 3 and 4). According to the model, Atlantic SST anomalies do not exert a strong influence on Southeast winter half-year precipitation.

The patterns of GOGA and POGA-ML ensemble mean SLP associated with Niño-3.4 SST anomalies do not vary over time. The single pattern shows the strong North Pacific low during El Niños but does not show the strong low that occurred over the Atlantic in the 1922-50 period (not shown). If ENSO teleconnections varied in time in a way that created a time-varying relation 
a) $\quad 1895-1921$

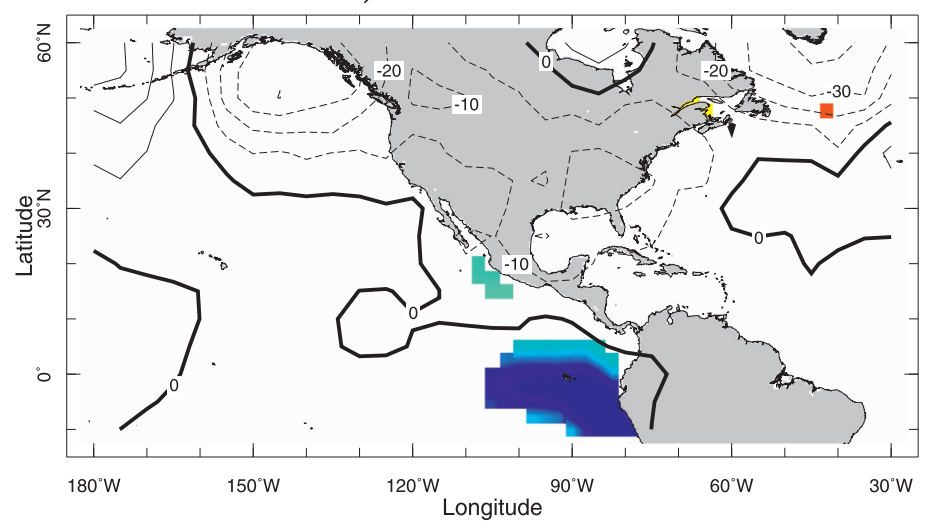

b) $\quad 1922-1950$

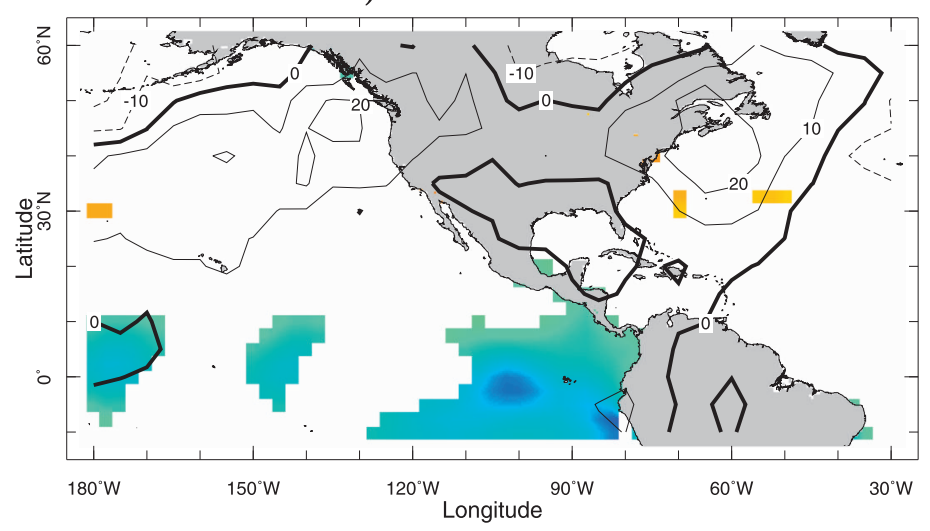

c) 1951-2004
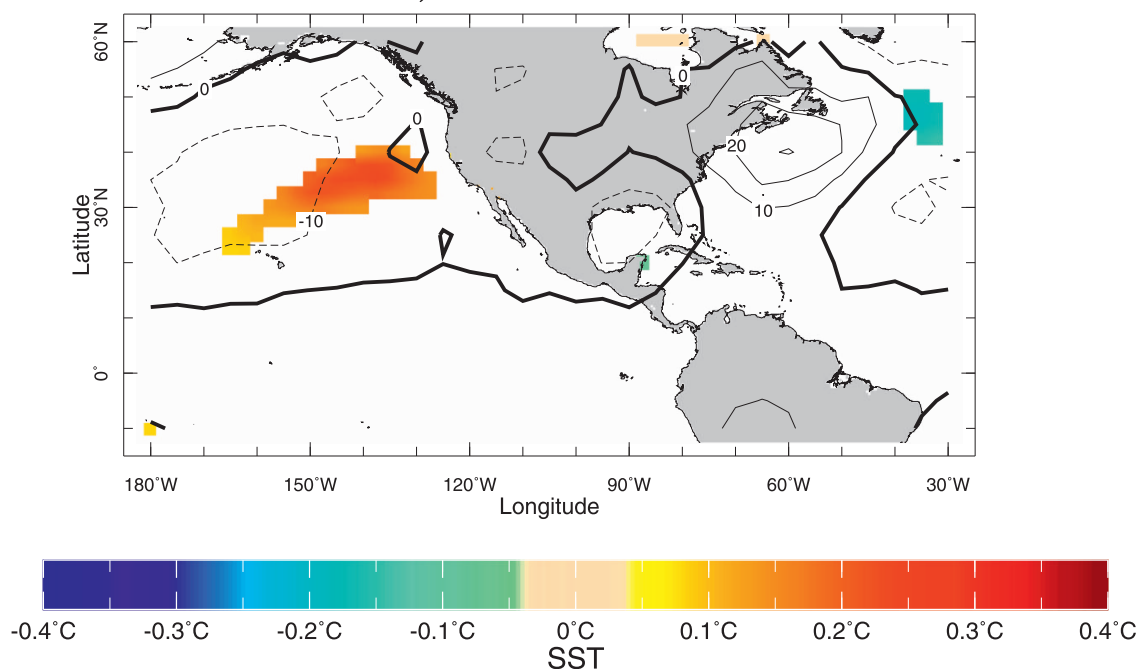

FIG. 5. Same as Fig. 3 but for May through October.

between Southeast precipitation and tropical Pacific SST anomalies, then this is not captured by the model.

The ensemble mean modeled summer half-year precipitation in the Southeast is related to modeled SST and
SLP in a manner that looks like a muted version of the winter half-year relationship; that is, wet summer halfyears in the Southeast are associated with a warm tropical Pacific Ocean. This is in marked contrast to the 
a) Nov-Apr

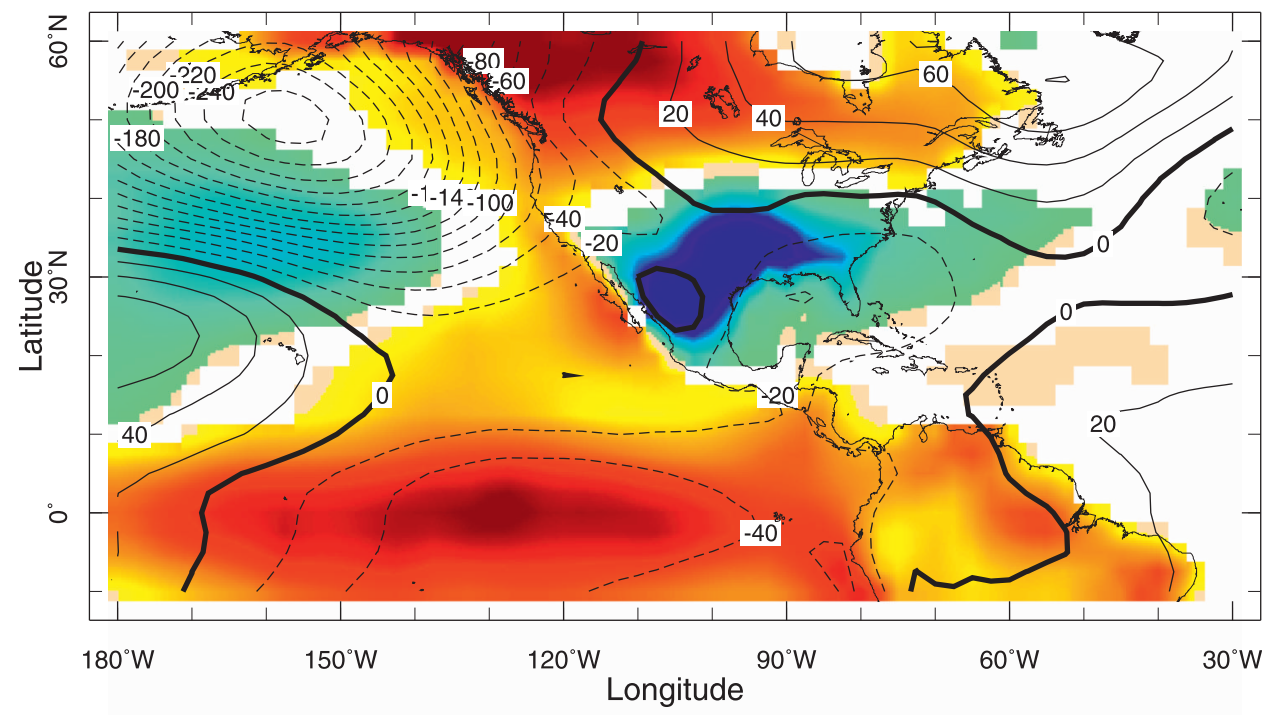

b) May-Oct
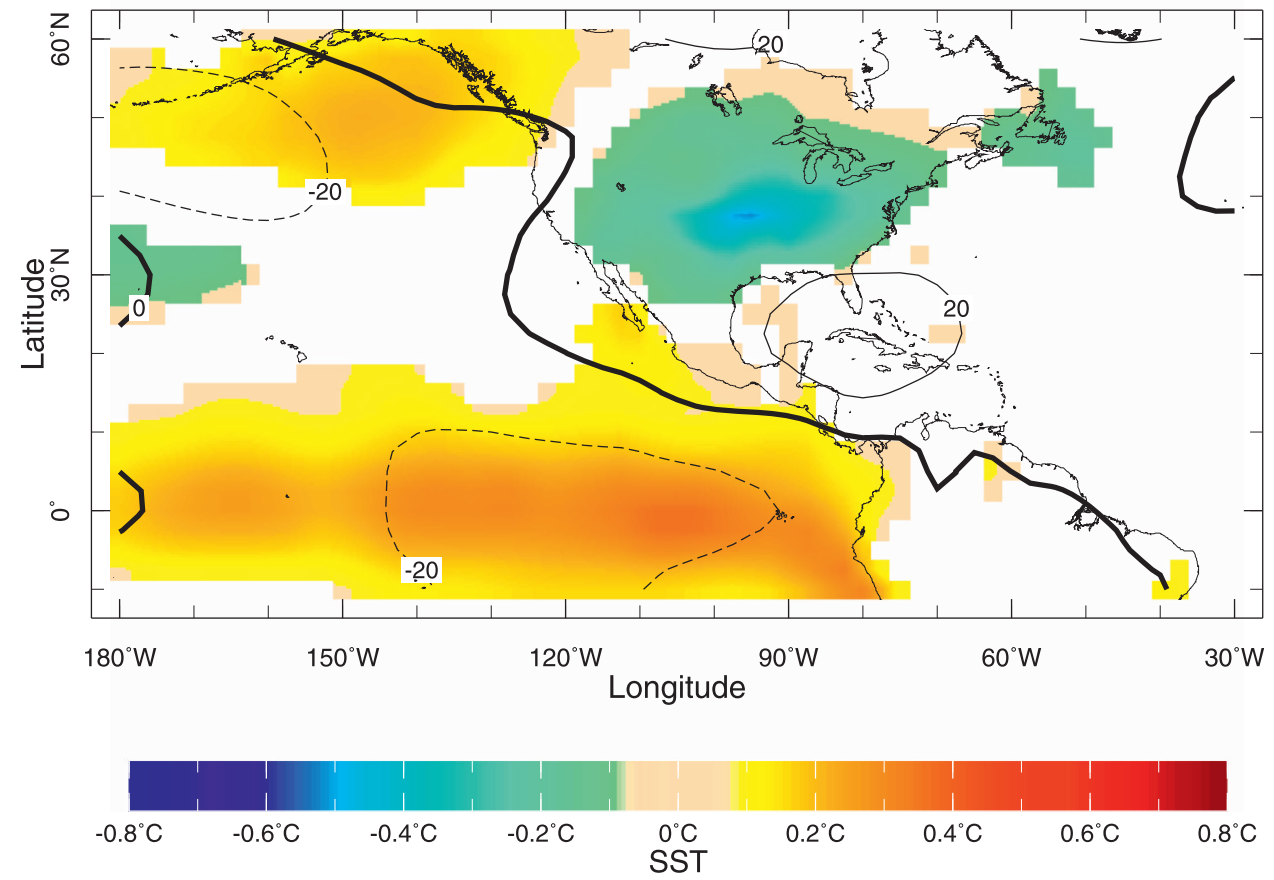

FIG. 6. The regression of the Southeast precipitation of land and SST (colors, ${ }^{\circ} \mathrm{C}$ ) and SLP (contours, $\mathrm{Pa}$ ), all from the GOGA model ensemble mean for the (top) November through April and (bottom) May through October half-years. Surface temperature values are only plotted where they are statistically significant at the $5 \%$ level.

observed relationship, which shows no obvious link to the tropical Pacific Ocean. However, the ensemble mean would be expected to emphasize the SST-forced component of Southeast precipitation variability which, if weak, could be overwhelmed in nature by internal atmospheric variability.

\section{d. Large-scale patterns of precipitation variability associated with variability in the Southeast}

An additional way to examine the possible causes of precipitation variability in the Southeast is to examine the large-scale patterns of precipitation variability in 
a) Nov-Apr

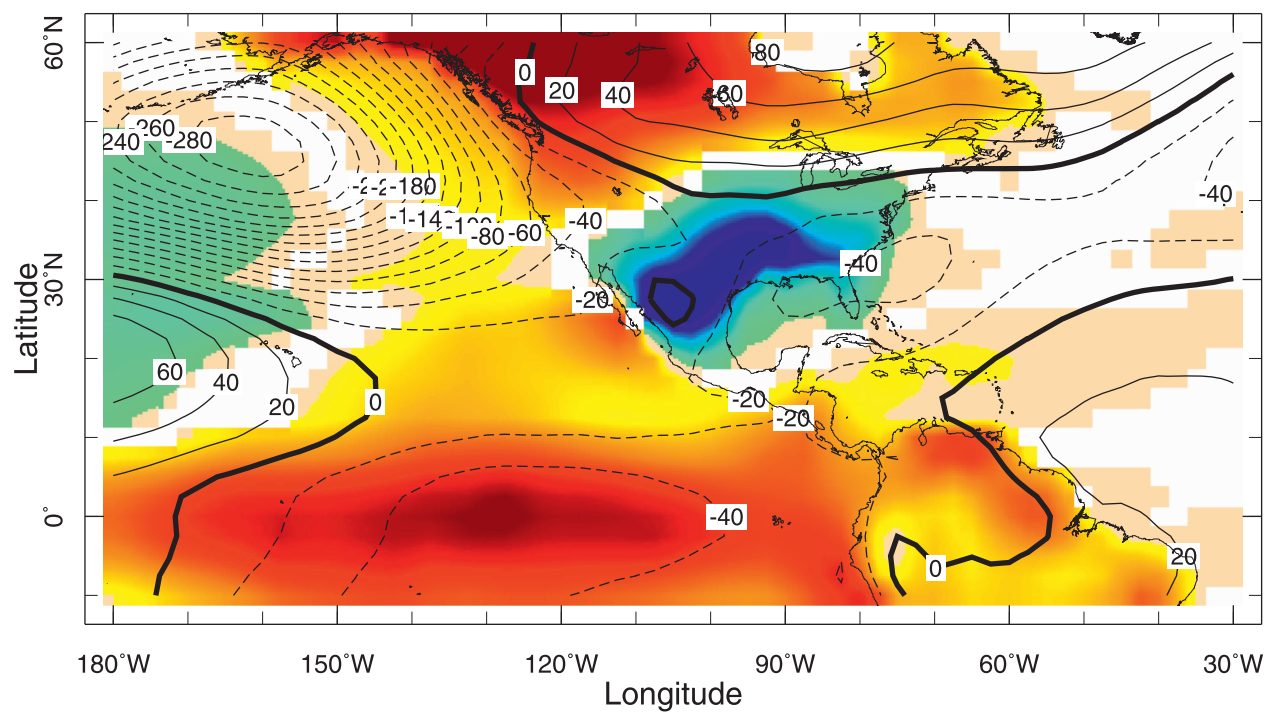

b) May-Oct
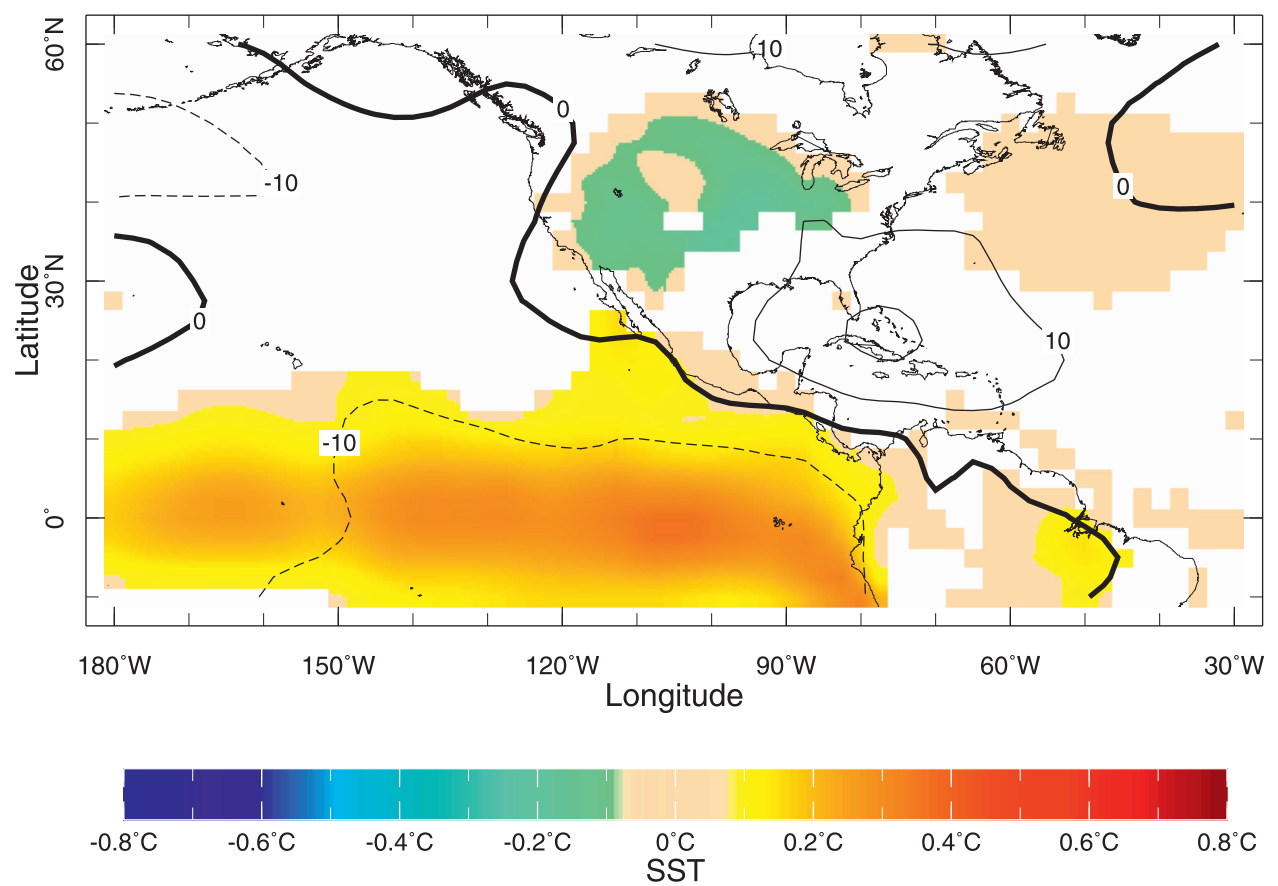

FIG. 7. Same as Fig. 6 but for the POGA-ML model ensemble mean.

which it is embedded. This can only be done with precipitation data over oceans as well as land and therefore we examine the GPCP combined gauge-satellite data from 1979 through 2007 as well as results from the GOGA ensemble mean using data from 1856 to 2007.

The observed winter half-year pattern (Fig. 8) affirms the link of wet Southeast winters to El Niño in the tropical Pacific, as evidenced by the equatorial band of positive precipitation anomaly there. The summer halfyear pattern appears largely local and has only a very weak link to the tropical Pacific Ocean. The GOGA modeled winter half-year pattern (Fig. 9), using the entire 1856-2007 record, is also linked to El Niño and is quite realistic (the patterns are not appreciably different when we only use the post-1979 model data to match the shorter observational record). However, during the 
summer half-year, the model also produces a link, albeit weaker, between wet in the Southeast and wet over the equatorial Pacific that is at variance with the observations. That said, there is evidence for a summer halfyear teleconnection from the tropical Pacific to the Caribbean-Gulf of Mexico-Mexico-southern U.S. region (Seager et al. 2009). However, this teleconnection pattern has a nodal line in its precipitation anomaly close to the Southeast. ${ }^{2}$ It is therefore not surprising that in the single realization of nature, any link of summer half-year Southeast precipitation to the tropical Pacific is overwhelmed by internal variability. In contrast, the model ensemble mean, by averaging over the internal variability, shows the weak connection to the tropical Pacific. The spatial patterns obtained from the POGAML model (not shown) are essentially the same as those shown from the GOGA model, emphasizing the role of the tropical Pacific in the model.

\section{e. Comparison of ensemble mean modeled and observed history of Southeast precipitation in the instrumental period}

The model data comparisons conducted so far suggest that the ensemble means of simulations forced by historical SSTs should be able to capture some part of the observed winter half-year precipitation variations in the Southeast but should have no ability to reproduce the summer half-year variations because those are strongly influenced by internal atmosphere variability. This supposition is confirmed by Fig. 10, which shows the time series of observed climate division and GOGA ensemble mean modeled precipitation for the summer and winter half-years for the Southeast. The correlation coefficient between the winter half-year observed and ensemble mean modeled time series is very low-only 0.13 -indicating the model is capturing only a very small part of the observed variance since 1895 . However, as expected given the time-varying strength of the Southeast precipitation-ENSO connection (Fig. 3), the correlation coefficient varies between 0.33 for the 19512007 period, 0.32 for the pre-1922 period, and -0.41 for the $1922-50$ period.

As expected, the modeled and observed summer halfyear precipitation time series are uncorrelated (Fig. 10).

\footnotetext{
${ }^{2}$ Indeed, by moving the longitude ranges of the box used to define the Southeast precipitation index, or even by including ocean points within the range used, wet conditions become correlated with La Niña in the tropical Pacific as the precipitation index picks up the coherent region of precipitation teleconnection that extends from east of the southeastern United States southward, eastward, and westward over the Gulf of Mexico, Caribbean Sea, and adjacent Atlantic Ocean.
}

This is consistent with summer precipitation variations in the Southeast arising from internal atmospheric variability and not from SST forcing. This is in part because the Southeast lies between an area to its west where summer precipitation is positively correlated with tropical Pacific SSTs and an area to its east and south that is negatively correlated (see Seager et al. 2009). In both half-years, the modeled precipitation variability is weaker than that observed, as evidenced by the frequent excursions of the latter outside of the two standard deviation spread of the model ensemble (as shown by the shaded area in Fig. 10).

It is interesting that, despite its proximity to the Atlantic Ocean, neither observational analysis nor the model results have indicated an influence of SST anomalies on Southeast precipitation. This is confirmed by the TAGA ensemble, which produces only very weak precipitation anomalies over the Southeast that are poorly or not correlated with observations (not shown). The POGA-ML ensemble allows Atlantic SSTs to respond to tropical Pacific forcing, which has been shown to create a negative feedback on precipitation over western North America. However, when the tropical Pacific SST forcing is isolated in the POGA ensemble, the results for the Southeast (not shown) are not significantly changed from the coupled POGA-ML ensemble, emphasizing the direct effect of the Pacific on the Southeast.

These results are not unique to this model. We also created plots like Fig. 10 for ensembles of historical model simulations archived at the International Research Institute for Climate and Society (available online at http://iridl.ldeo.columbia.edu/docfind/databrief/ cat-sim.html): the Center for Ocean-Land-Atmosphere Studies (COLA) model (10 members, 1950-2003); the National Aeronautics and Space Administration's (NASA) Seasonal-to-Interannual Prediction Program (NSIPP) model (9 members, 1930-2008); the European Centre for Medium Range Weather Forecasts-Hamburg, version 4.5 (ECHAM4.5) model (24 members, 19502007); the Geophysical Fluid Dynamics Laboratory atmospheric model 2.1 (GFDL AM2.1; 10 members, 1950-1999); and the NCEP model (10 members, 19502004). The correlation coefficients between modeled and observed winter half-year precipitation (for the same southeastern land area as used before) were 0.20 for NSIPP, 0.27 for COLA, 0.42 for ECHAM4.5, 0.38 for GFDL, and 0.22 for NCEP. These are comparable to that from our GOGA simulations, given that the other models primarily contain the late-twentieth-century period of highest correlation.

Summer half-year precipitation was essentially uncorrelated, or even weakly negatively correlated, with 
a) Nov-Apr

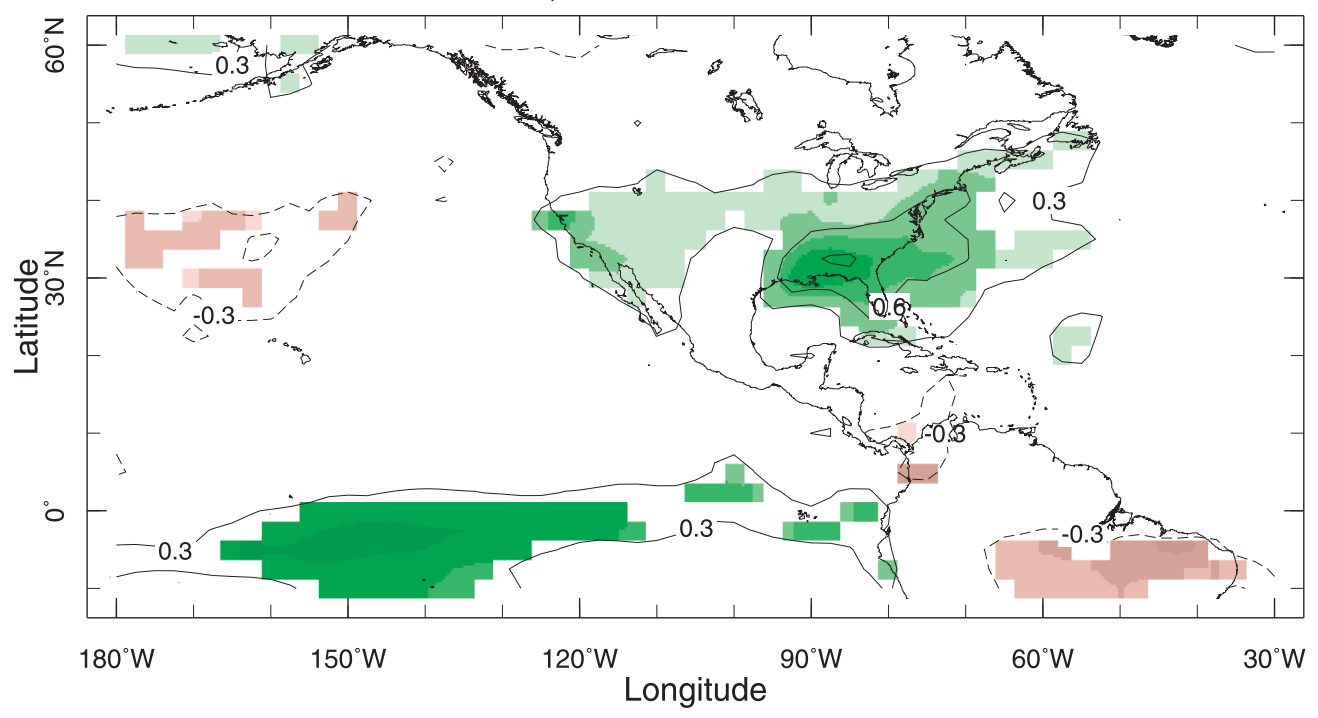

b) May-Oct
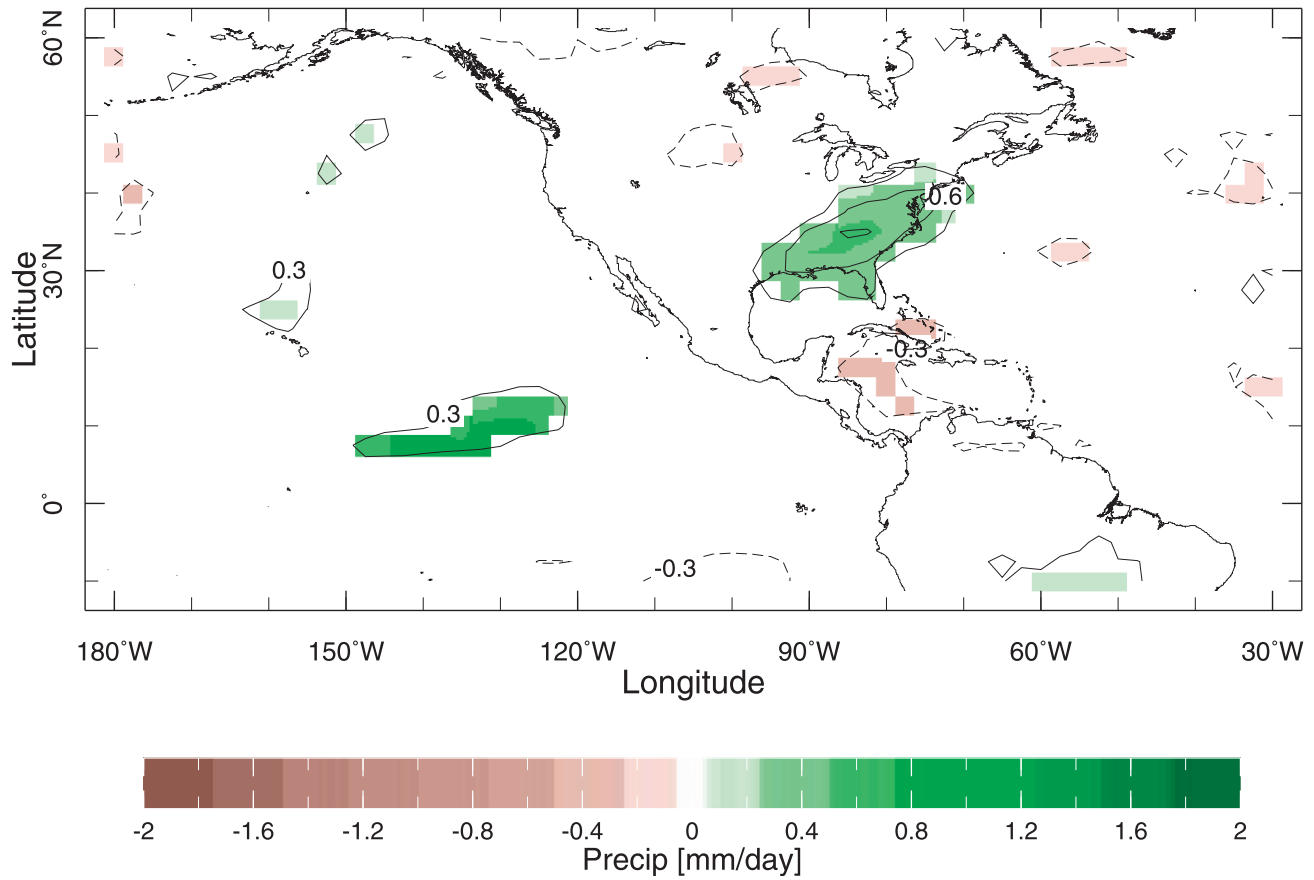

FIG. 8. The regression (and correlation between GPCP satellite-gauge precipitation and an index of that over the Southeast for the (top) November through April and (bottom) May through October half-years using data from 1979 through 2007. The regression coefficients (colors) are only plotted where significant at the 5\% level, and the correlation coefficient is contoured. Units for the regression are millimeters per day per standard deviation of the Southeast precipitation index.

observations for four of these additional models; however, it reached 0.29 for the NCEP model. Unlike the other models, precipitation in the Southeast in the NCEP model was weakly correlated to La Niña conditions. However, there is no evidence from the observational analyses presented here, or from an analysis of the spatial pattern of ENSO-associated GPCP precipitation anomalies, that this is a generally correct or robust relationship and therefore we avoid the conclusion that the NCEP model is right and the other five models are wrong. 
a) Nov-Apr

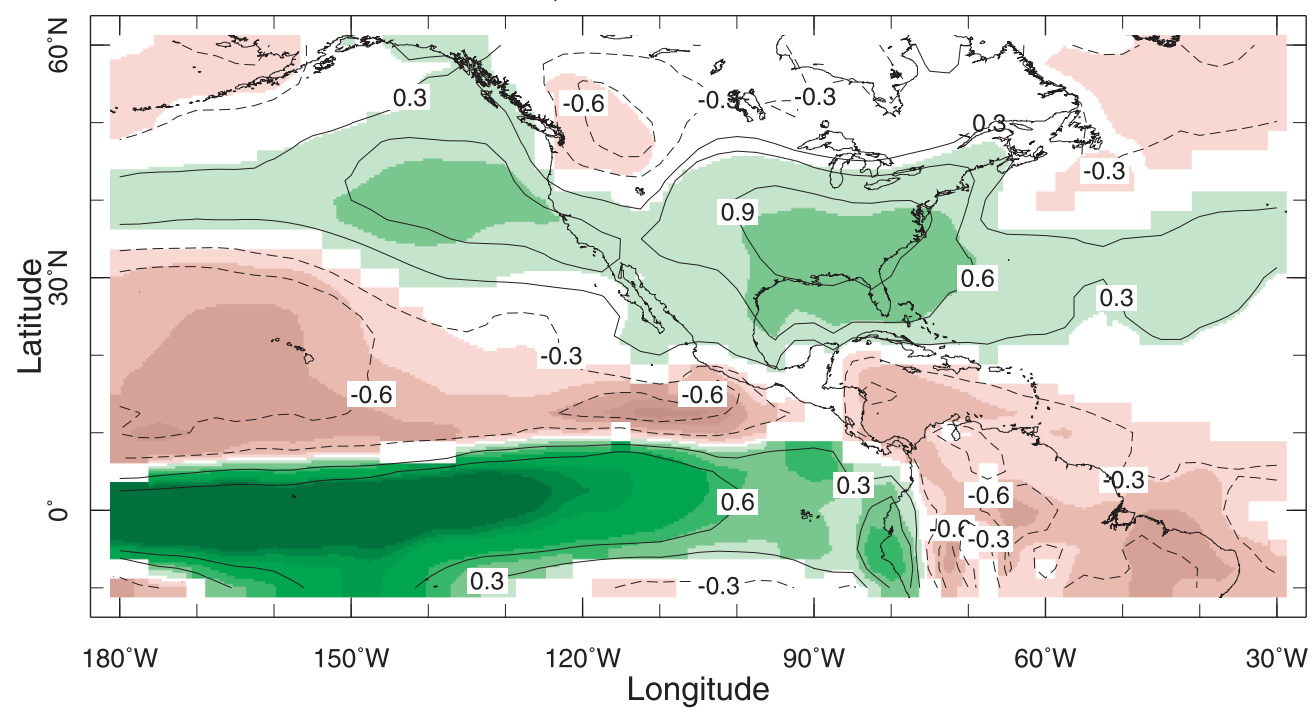

b) May-Oct
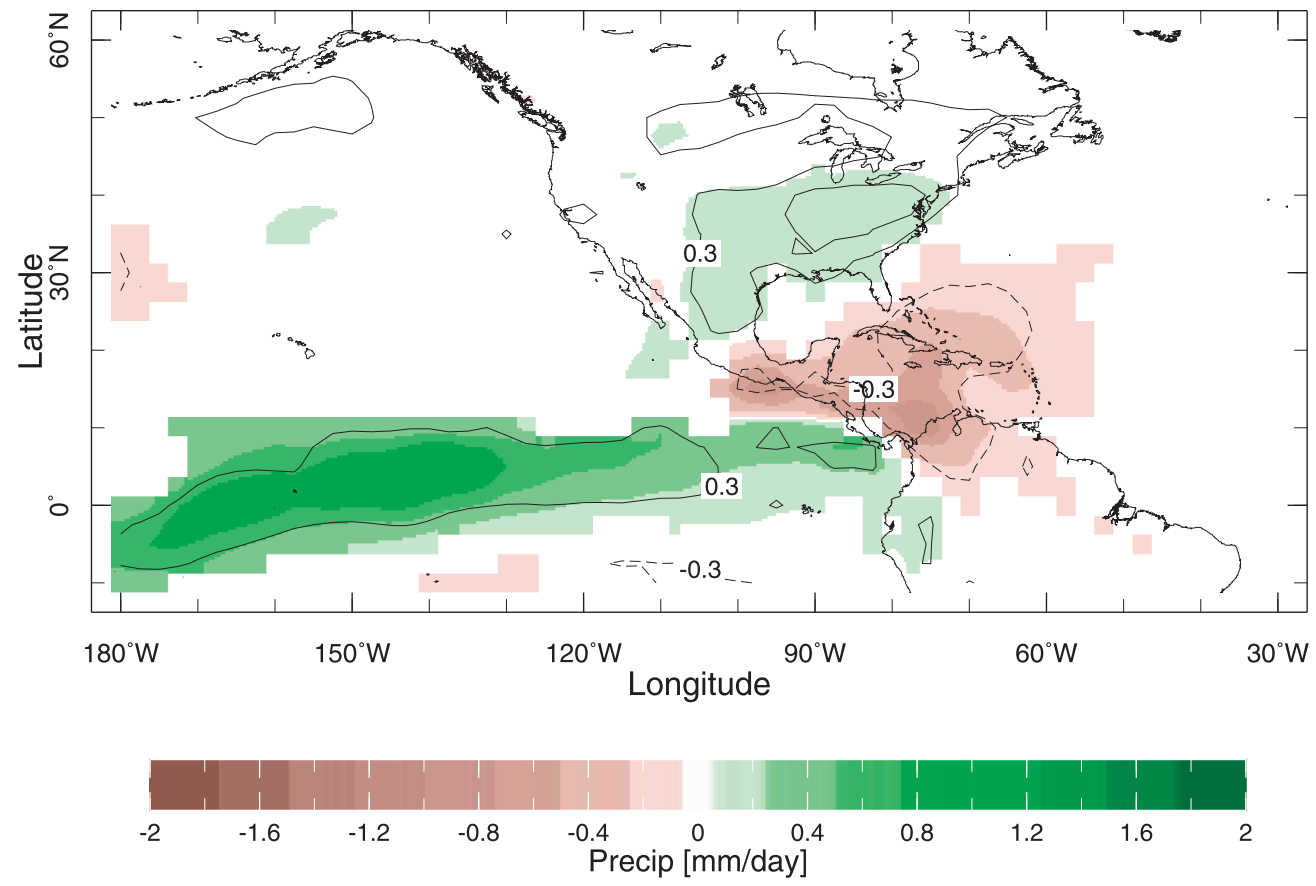

FIG. 9. Same as Fig. 9 but for the ensemble mean of the GOGA simulations. Units for the regression are millimeters per day per standard deviation of the GOGA Southeast precipitation index.

Given the weak relationship between Southeast precipitation and SSTs, and the varying SST conditions in the tropical Pacific Ocean during the 2005-07 period, it is not surprising that the GOGA model fails to accurately reproduce a continuous drought from winter 2005/06 through fall 2007. The modeled precipitation anomalies are shown in Fig. 11 (cf. Fig. 1) and show a very limited hindcast skill. Of the four half-years that made up the drought period, only the La Niña-associated dry winter of 2005/06 is convincingly simulated. In contrast, the model conspicuously fails to simulate the dry Southeast from November 2006 through October 2007. The simulations from the tropical Pacific-forcedonly model (POGA-ML) are also shown in Fig. 11 and 

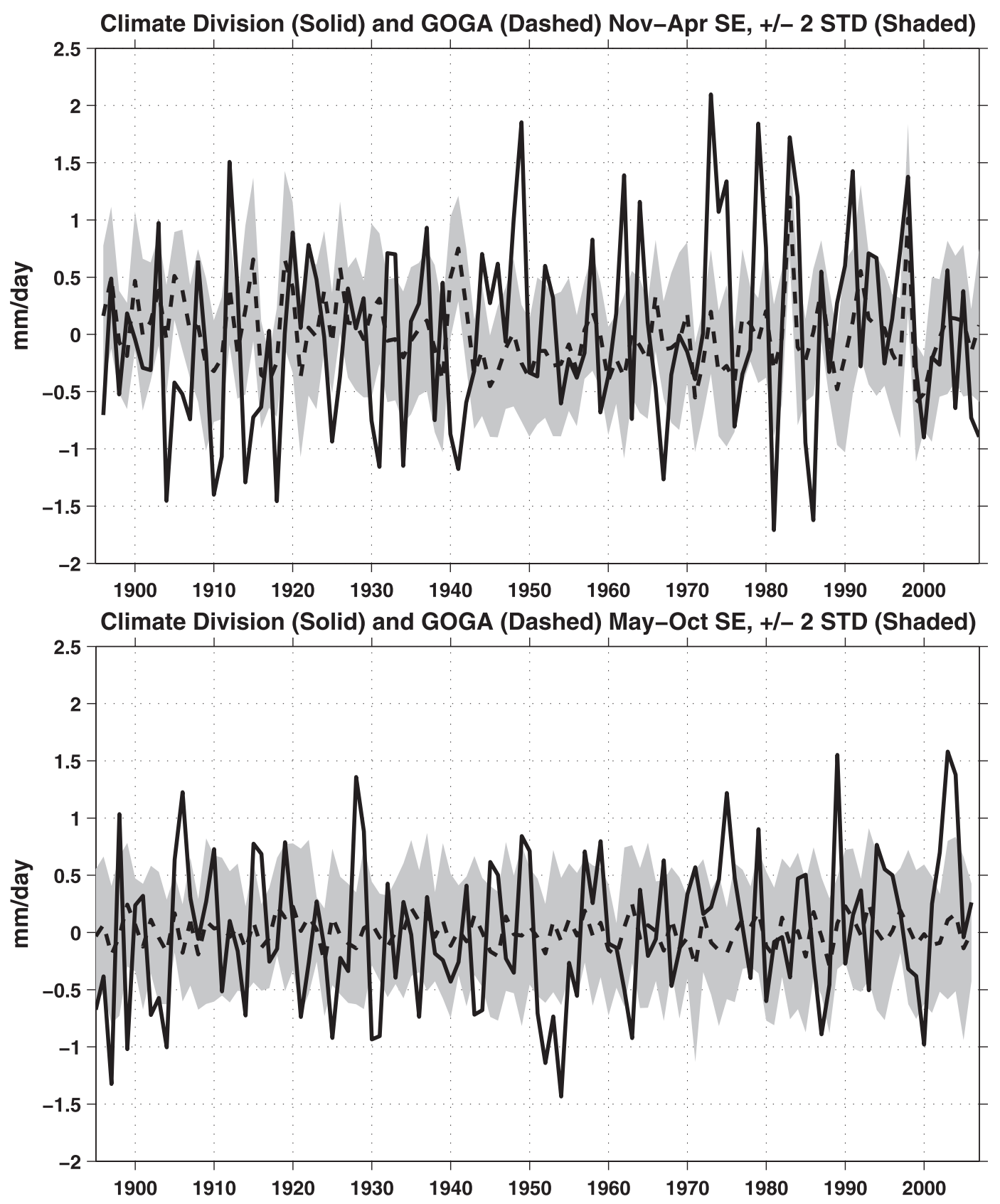

FIG. 10. Time series of the climate division precipitation averaged over the Southeast and that of the GOGA ensemble mean $\left(\mathrm{mm} \mathrm{day}^{-1}\right)$ for the (top) winter and (bottom) summer half-years. The shading around the model time series shows the plus and minus two standard deviation of the spread within the model ensemble. Model skill is weak (nonexistent) during the winter (summer) half-years.

are essentially very similar to the results obtained with global SST forcing, emphasizing the dominance in the model of the tropical Pacific forcing. The only two other models that cover the recent drought-NSIPP and ECHAM4.5-produced similar results (not shown).

In contrast to the failure of the model to simulate the post-2005 drought as a response to SST forcing,
Fig. 10 shows that the preceding turn-of-the-century drought was more accurately simulated during the winter half-year by the GOGA model [and also by the other models (not shown)] probably because, in nature and the model, this was a response to a continuous 4-yr La Niña (Hoerling and Kumar 2003; Seager 2007). 
Nov 2005 - Apr 2006
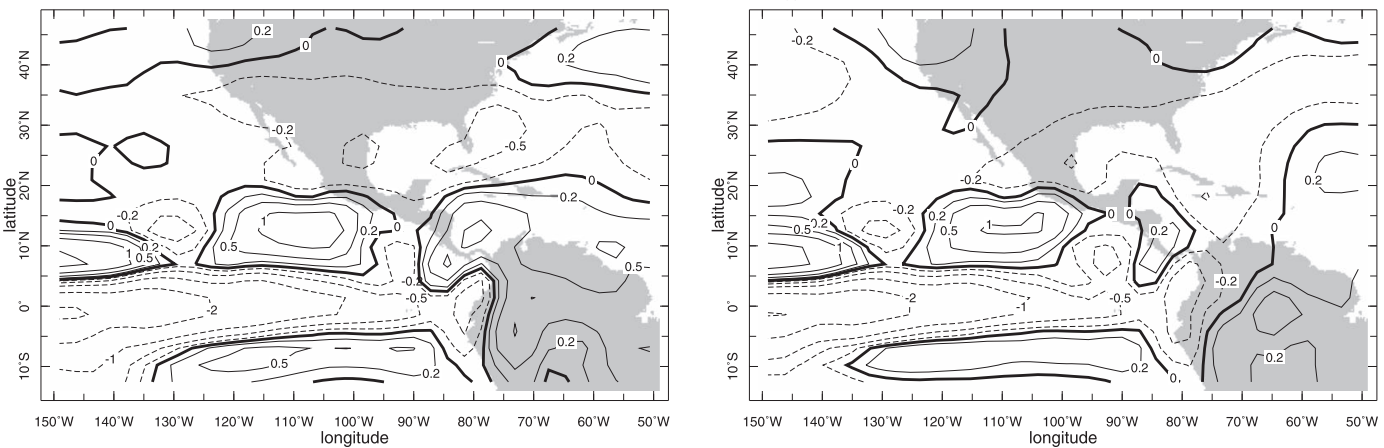

May 2006 - Oct 2006
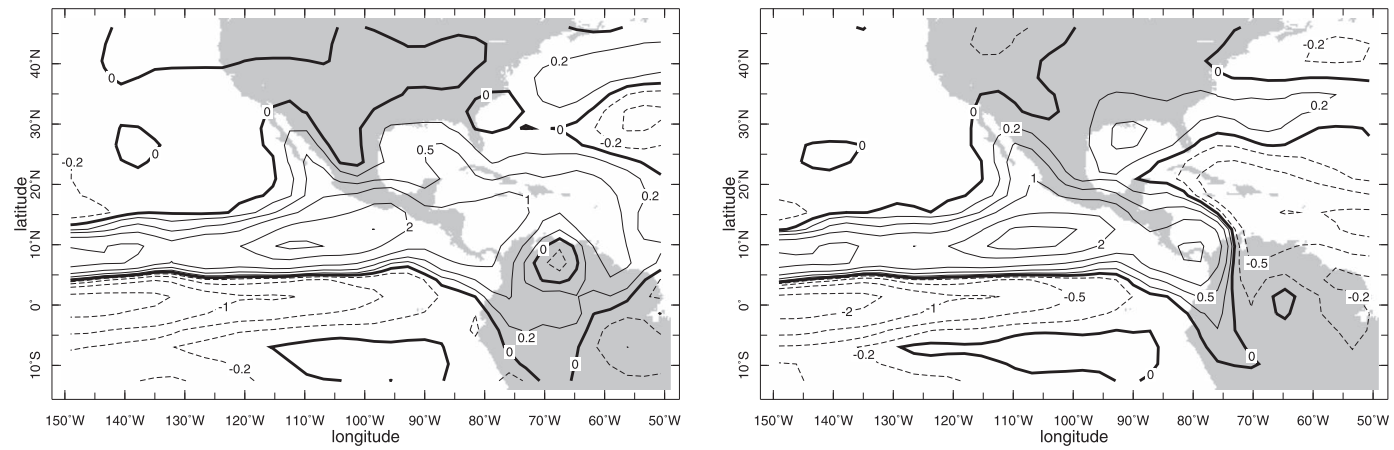

Nov 2006 - Apr 2007
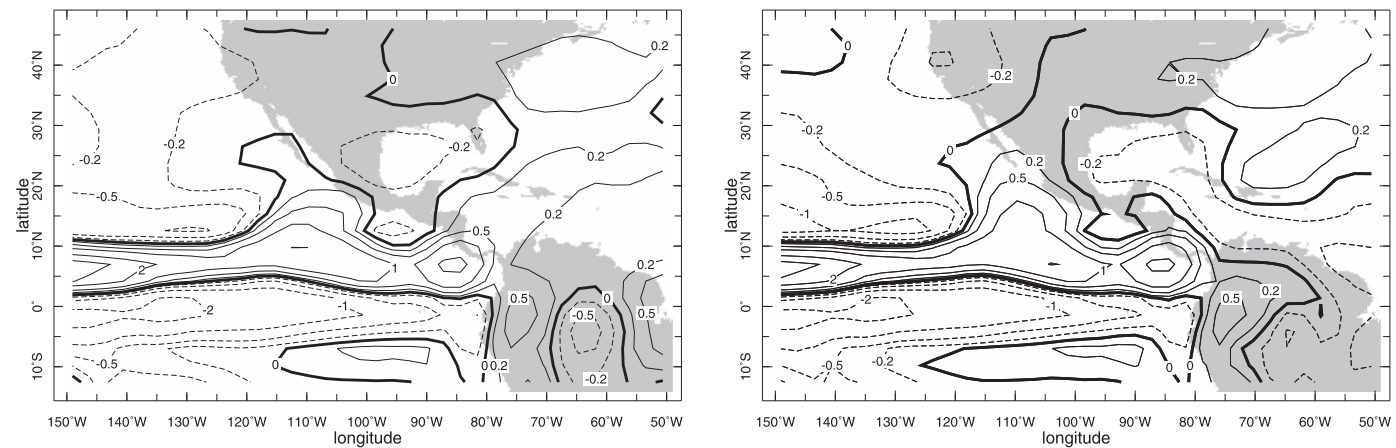

May 2007 - Sep 2007
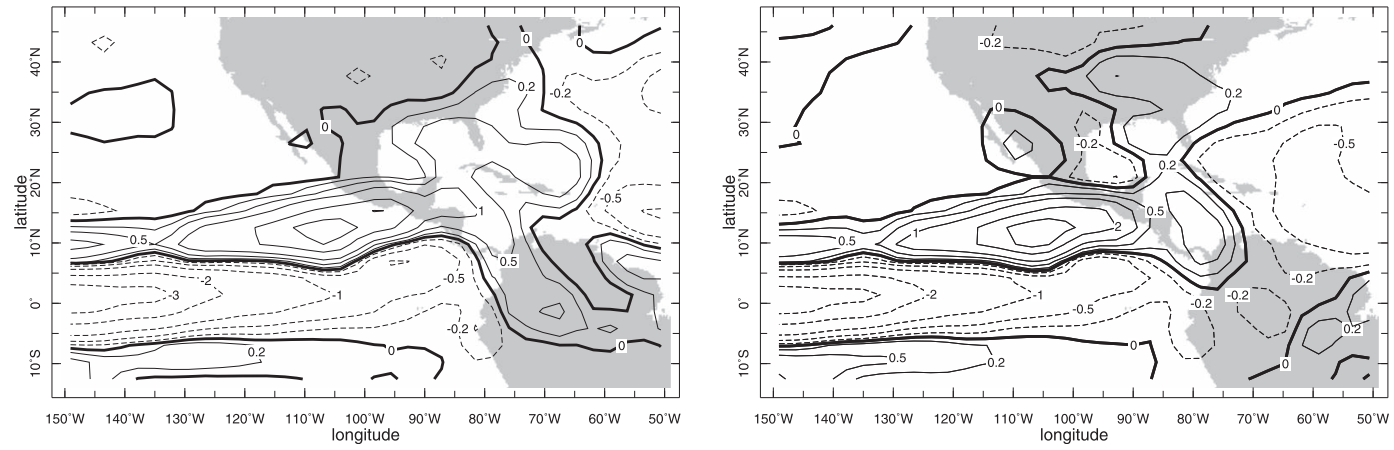

FIG. 11. The modeled precipitation anomalies $\left(\mathrm{mm} \mathrm{day}^{-1}\right)$ for half-years from winter 2005/06 through 2007 for the case of (left) global SST forcing (GOGA) and (right) tropical Pacific forcing alone (POGA-ML). Results are shown for the Pacific-North America-Atlantic domain, and anomalies are relative to a post-1979 climatology to facilitate comparison to the satellite-gauge results shown in Fig. 1. 


\section{f. Summary: Causes of Southeastern drought}

The observational record that winter precipitation in the Southeast is tied to ENSO, as has been noted by many before, beginning with Ropelewski and Halpert (1987), is supported in a cause-and-effect manner by modeling experiments in which times of cool tropical Pacific SSTs force drier-than-normal conditions in the Southeast. However, this relationship is weak in the observational record and, what is more, was not operative at all between about 1922 and 1950, during which time Southeast precipitation does not appear to be controlled by any known mode of SST-forced climate variability. In contrast, the model ensemble mean produces a very stable relation between cool tropical Pacific SST anomalies and dry SST anomalies in the Southeast.

These results can be reconciled by recognizing that, even during the time of an active ENSO-Southeast precipitation relation, ENSO explains at most a quarter of the Southeast precipitation variance. The model ensemble mean isolates the SST-forced signal and, by design, produces a stronger ENSO-Southeast precipitation relation. During the approximately 1922-1950 period, the modest ENSO-forced signal in Southeast precipitation was not evident. The results of Gershunov and Barnett (1998) suggest that the dominantly positive PDO during this time acted to weaken the ENSO-Southeast precipitation link, leaving winter half-year precipitation variability in nature to be dominated by internal atmosphere variability, which the model ensemble mean, by design, filters out.

In the summer half-year, the observed precipitation variations seem only related to internal atmosphere variability and not to any SST forcing. In contrast, the model creates wetter-than-normal summer half-years when tropical Pacific SSTs are warm. This would lead to a spurious prediction, but the large ensemble spread and weak correlation would caution about placing any faith in the ensemble mean prediction. Consistent with these results is that the time history of modeled and observed precipitation in the Southeast shows only weak agreement in the winter half-year and no agreement in the summer half-year. Similarly, low model skill was obtained when examining simulations conducted for shorter periods of time with five other climate models and confirms the limited potential predictability of Southeast precipitation in winter and its unpredictability in summer.

The atmospheric dynamics that link tropical SSTs to precipitation variations in the North American and global extratropics have been analyzed in detail elsewhere (Seager et al. 2003; 2005a,b; Cook et al. 2007; Seager 2007; Seager et al. 2009) and will not be further examined here.

\section{Long tree-ring records of drought in the Southeast}

Does the short instrumental record capture all that can happen in the Southeast, or can droughts more serious than any in the instrumental record occur? To examine this question, we used an updated (by the inclusion of more tree-ring records; Ed Cook 2007, personal communications) version of the NADA, which provides tree-ring reconstructed summer PDSI for each year from 2 B.C. to A.D. 2006 (Cook and Krusic 2004; Cook et al. 2004). Before A.D. 1000, coverage is largely restricted to western North America, and here we examine the period from A.D. 1000 onward. Before proceeding we correlated the tree-ring reconstructed PDSI with the climate division precipitation data for the overlapping post-1895 period. The tree-ring PDSI correlated equally well with summer and winter half-year precipitation with a correlation coefficient of about 0.5 for both, or about a quarter of the variance being explained. Winter and summer precipitation are not well correlated in the Southeast. Consequently, a total of about half the tree-ring PDSI variance is explained by precipitation variations, with precipitation in each of the two half-years being about equally responsible. This is comparable to the correlation between precipitation and instrumental PDSI that Karnauskas et al. (2008) found for the Great Plains. The summer and winter correlations also suggest that the trees in the Southeast are sensitive to precipitation year around and therefore we think of the PDSI values as indicative of the annual moisture balance.

As shown in Fig. 12, the Southeast has experienced a rich amount of temporal hydroclimate variability over the last millennium. The dataset ends in 2006 and does not capture the recent drought in entirety, but the equally as severe turn-of-the-century drought (Seager 2007) is unremarkable and appears as one of many such short dry spells.

In addition to short and severe droughts, there is evidence of some long multiyear droughts. To search for these droughts, we created a criterion for a drought that begins with a year of negative PDSI and ends the year before a year of positive PDSI and in the intervening period contains no back-to-back years of positive PDSI. We then calculated the cumulative PDSI over the drought, so defined, and ranked the results. Maps of the selected droughts are shown in Fig. 13 along with the map of the NADA estimate of the 1998-2002 drought for reference. Two droughts-from 1798 to 1826 and from 1834 to 1861 - appear as extended dry periods. The mid-nineteenth-century drought was centered in the Southeast, whereas the earlier nineteenthcentury drought was centered in the central plains but 

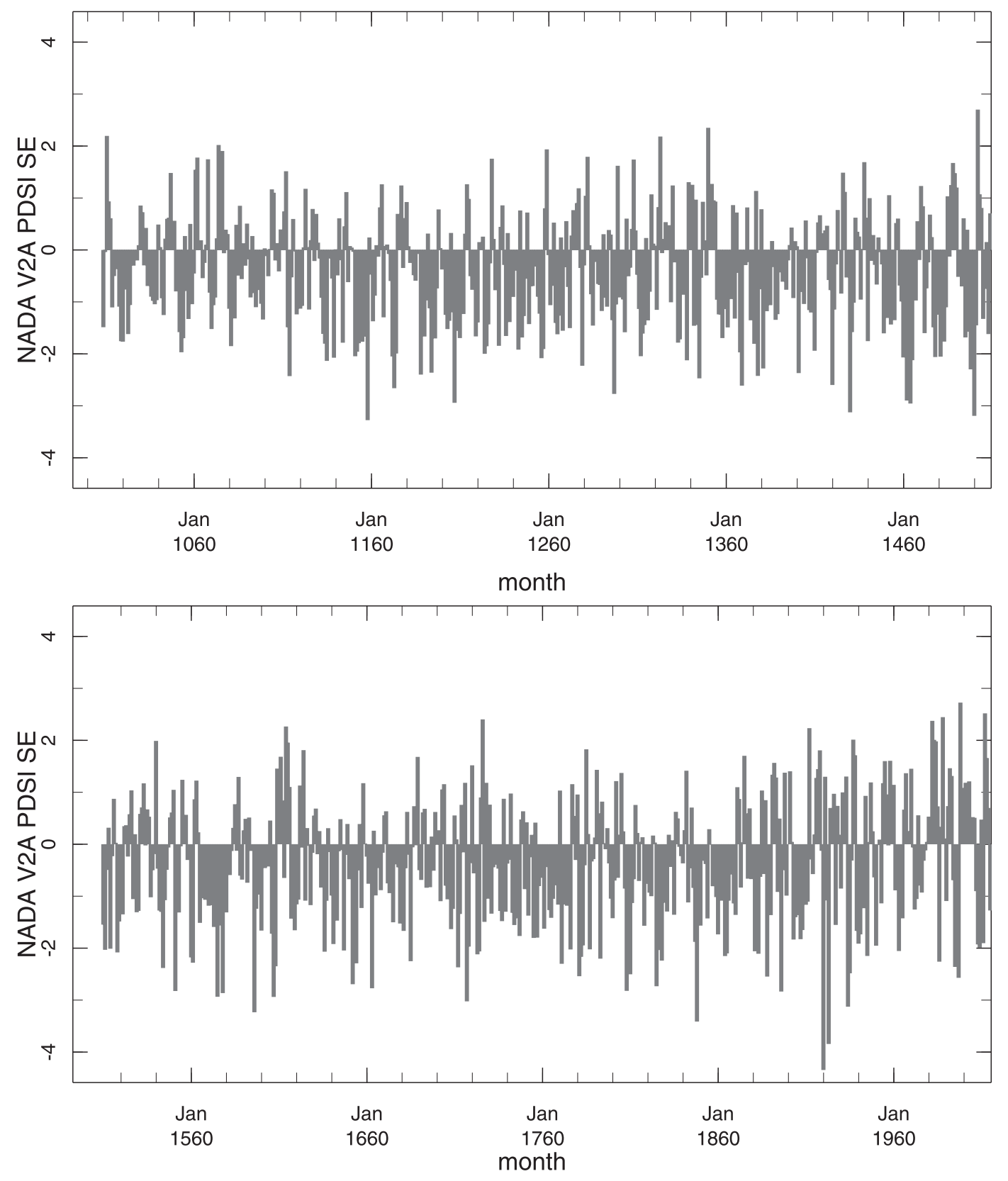

FIG. 12. The tree-ring reconstructed PDSI averaged over the Southeast for the A.D. 1000-2006 period from the updated NADA.

spread both east and west from there. In contrast, a strong and uninterrupted drought occurred in the eastern plains between 1555 and 1574 and also affected the Southeast but not the western United States. This drought corresponds to the earlier part of the sixteenthcentury megadrought identified by Stahle et al. (2000, 2007). In contrast yet again, the two medieval-era droughts selected affected both the West and the Southeast and are more akin in spatial pattern to prior identified medieval "megadroughts" (Herweijer et al.
2007; Seager et al. 2007a). The PDSI averaged over these droughts does not reach the severity of the 19982002 period, but the selected droughts generally include shorter periods within them of that severity and are much longer than the turn-of-the-century drought.

The early- and mid-nineteenth-century droughts are clearly seen in Fig. 12, and each drought included a few years with drought severity comparable or exceeding those in the turn-of-the-century drought and, more importantly, for 29 and $28 \mathrm{yr}$, respectively, each had 
a) $1998-2002$

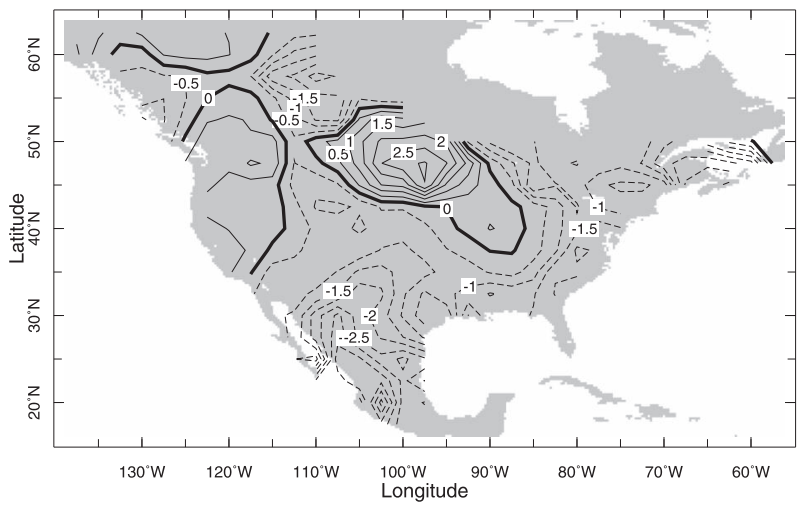

c) $1798-1826$

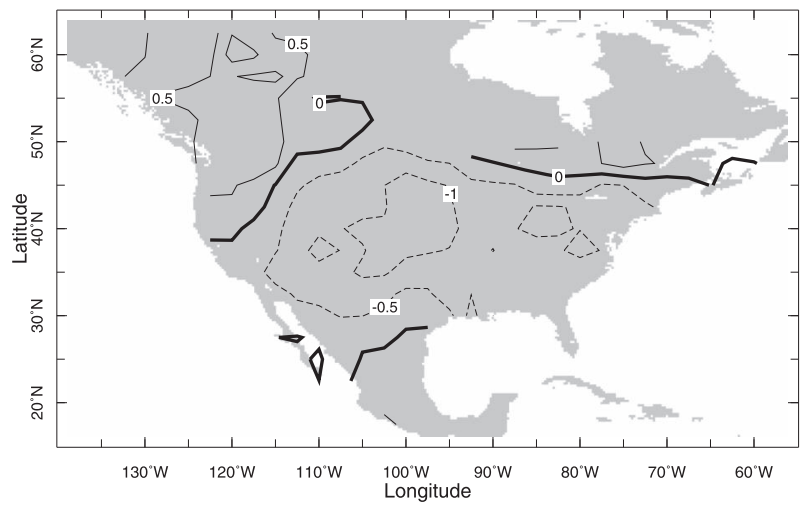

e) 1346-1401

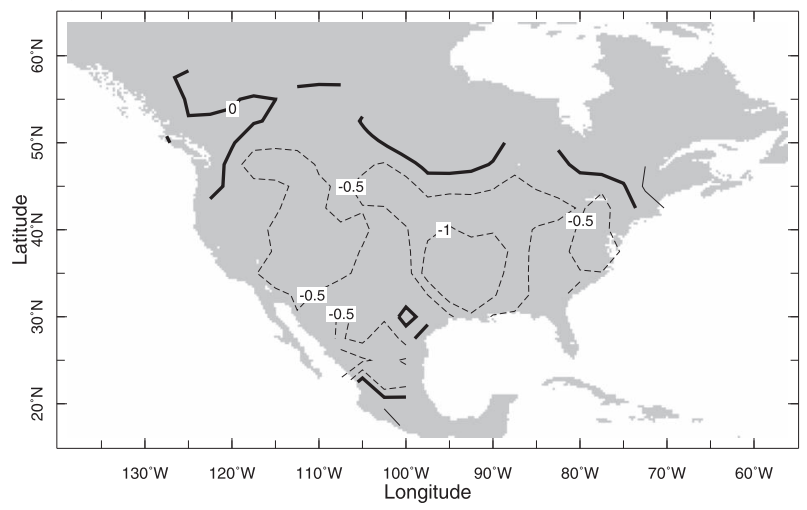

b) $1834-1861$

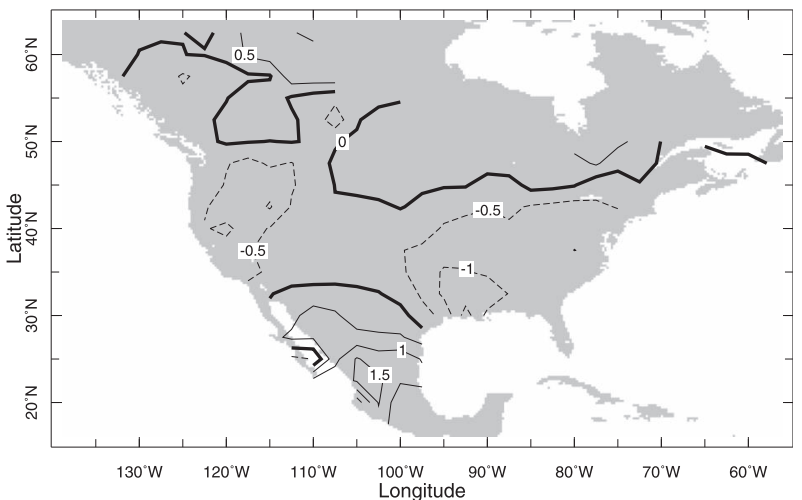

d) $1555-1574$

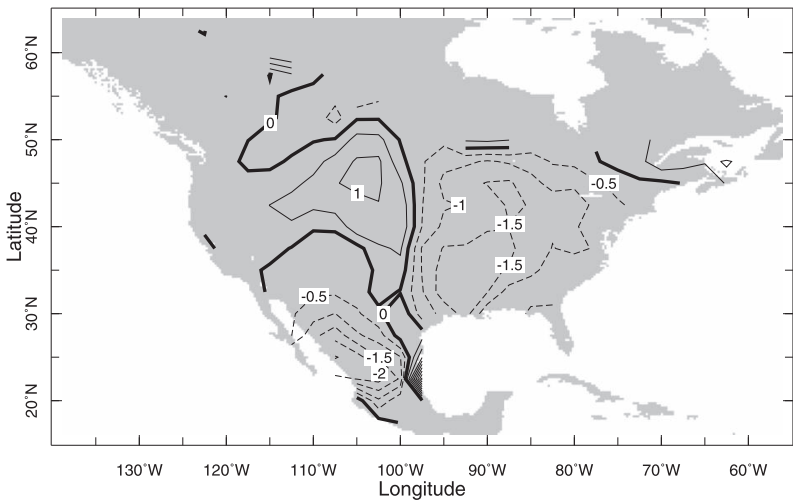

f) $1142-1155$

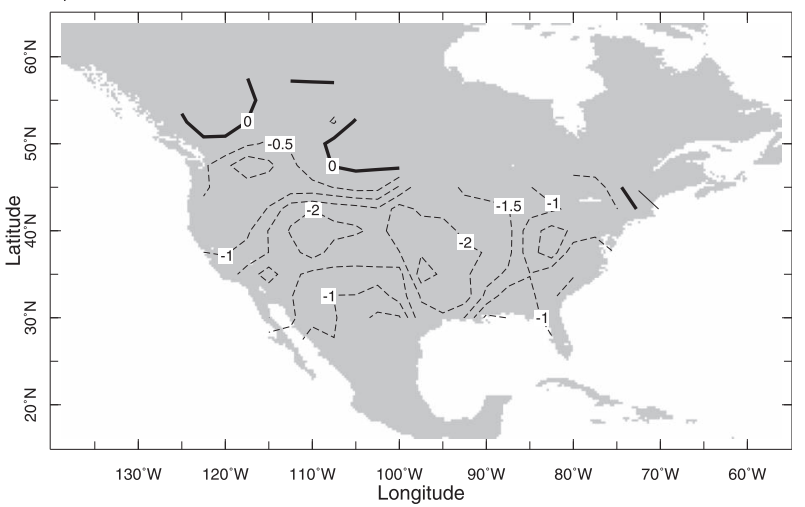

FIG. 13. Tree-ring reconstructions of PDSI for the turn-of-the-century drought and for five previous multiyear droughts as recorded in the NADA. The five earlier droughts were chosen on the basis of both longevity and intensity to illustrate the potential in the Southeast for multiyear-decadal time-scale droughts to occur.

overwhelmingly negative PDSI years and no years with more than extremely small positive PDSI. These nineteenth-century droughts, which are perhaps better thought of as a single multidecadal dry period, are well within the range of historical records and could potentially have had an agricultural effect but probably would not have had an effect on water availability for people given the generally wet climate of the Southeast and the much smaller population then as opposed to now. We are unaware of historical records of these droughts.

The causes of these long and severe droughts within the last millennium are not well known. The two widespread medieval-period droughts are potentially linked to cool tropical Pacific SSTs during those centuries (Cobb et al. 2003) according to mechanisms analogous to La Niña forcing of multiyear droughts (Cook et al. 


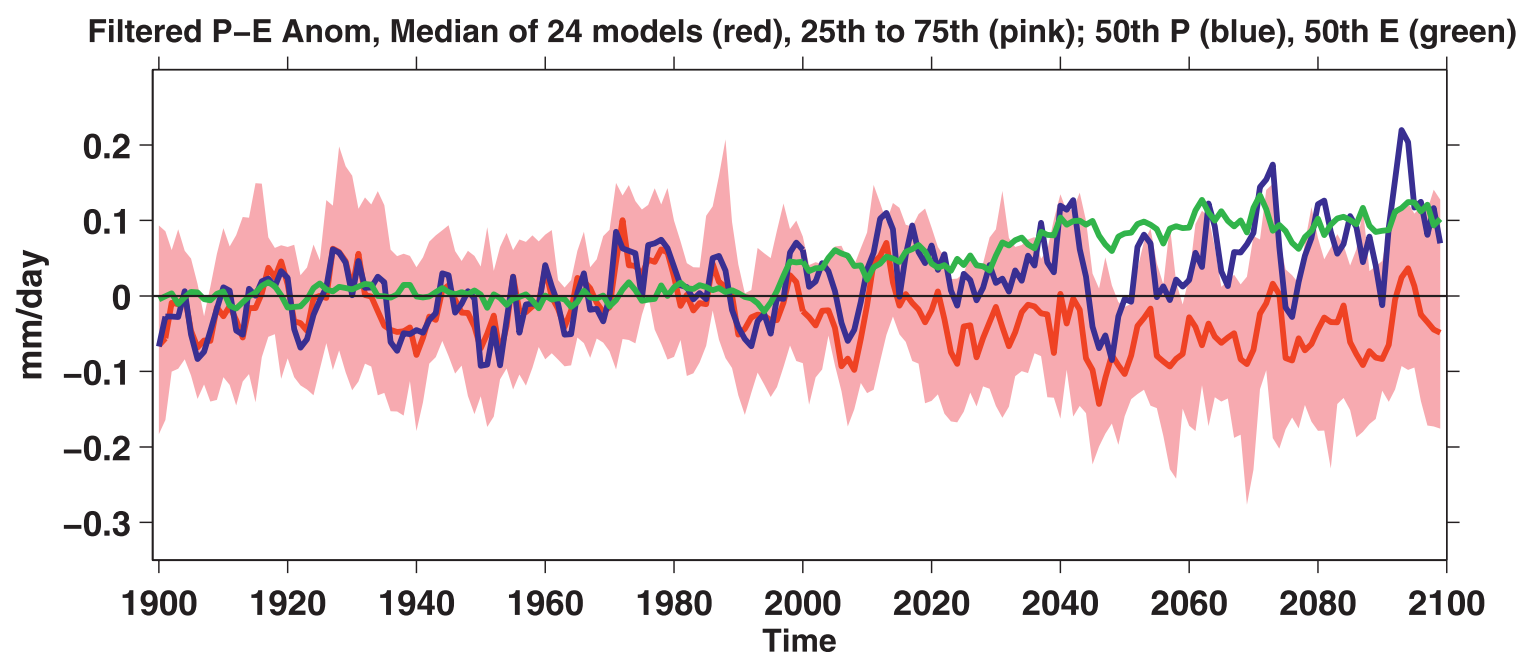

FIG. 14. Modeled changes $\left(\mathrm{mm} \mathrm{day}^{-1}\right)$ in annual mean $P-E$ over the Southeast $\left(30^{\circ}-38^{\circ} \mathrm{N}, 92^{\circ}-75^{\circ} \mathrm{W}\right.$, land areas only) averaged over ensemble members for each of the 24 models. The historical period used known and estimated climate forcings, and the projections used the SRES A1B emissions scenario. The red line shows the median $P-E$, and the pink shading shows the 25 th and 75 th percentiles of the $P-E$ distribution among the models. The ensemble medians of $P$ (blue line) and $E$ (green line) are also shown. Results are for the period common to all models (1900-2098) and anomalies for each model are relative to that model's climatology for 1950-2000. Results have been 6-yr low-pass Butterworth filtered to emphasize low-frequency variability. The climatological 1950-1999 model ensemble mean $P-E$ in this region is around $0.8 \mathrm{~mm}^{\mathrm{day}^{-1}}$.

2007; Herweijer et al. 2007; Seager et al. 2007a; Graham et al. 2007; Seager et al. 2008a) that created coast-tocoast droughts across southern North America. The link between the tropical oceans and the later droughts has not yet been examined. There is no indication in the record of a multicentennial medieval period of drier conditions in the Southeast as there is in the West (Cook et al. 2004; Herweijer et al. 2007; Seager et al. 2007a). However, it does seem that the twentieth century has, from the perspective of the millennium, been anomalously wet overall.

\section{Model projections of anthropogenic hydroclimate change in the Southeast}

There is no clear evidence of hydroclimate change in the Southeast during the period of anthropogenic forcing of climate (Fig. 2), but it is worth examining model projections of twentieth- and current-century change. To do this we have examined the simulations of the climate of the last century and projections of the climate of the current century that were done as part of the IPCC AR4 process. We examined results from all 24 models. Since for some models there are multiple simulations and projections and since we did not want to bias the results to any particular model, we only examined a single twentieth-century run and a single twentyfirst-century run for each model. Figure 14 shows time series of the annual mean medians of precipitation $(P)$ and evaporation $(E)$ from the multimodel ensemble as well as the median, and upper and lower quartiles, of the distribution of $P-E$.

The median projection for the Southeast is for both increasing $P$ and $E$. The balance is such that the median $P-E$ decreases very modestly during this century; $P-E$ drops more in the summer half-year than the winter half-year (not shown). However, the range of model projections is large with a quarter to a third of the models projecting an increase of $P-E$. Indeed, when the same 19 models as used by Seager et al. (2007b) are analyzed, a more striking reduction of $P-E$ appears, whereas a 12-member subset of models analyzed by Milly et al. (2005) shows an increase in implied runoff (and hence, presumably, in $P-E$ ) in the current century.

For the full 24-model ensemble, Fig. 15 shows maps of the annual mean change in $P$ and $P-E$ for the nearfuture period from 2021-40 minus the period from 1950 to 1999 . The Southeast clearly lies at the poleward fringe of the region of projected subtropical drying (Held and Soden 2006). In both half-years, $P$ increases over the Southeast in the projected near future. However, $P-E$ drops across the region in the summer half-year and for the southern part of the region in the winter half-year. Remembering that long-term mean $P-E$ is always positive over land, the reduction in $P-E$ implies less atmospheric convergence of moisture into the region in the near future. Since $P$ itself increases, this is driven by increased evaporation of fallen $P$ and its removal as vapor by the atmospheric flow. This is a very different 


\section{Precipitation}

\section{Precipitation - Evaporation}

\section{Nov-Apr}
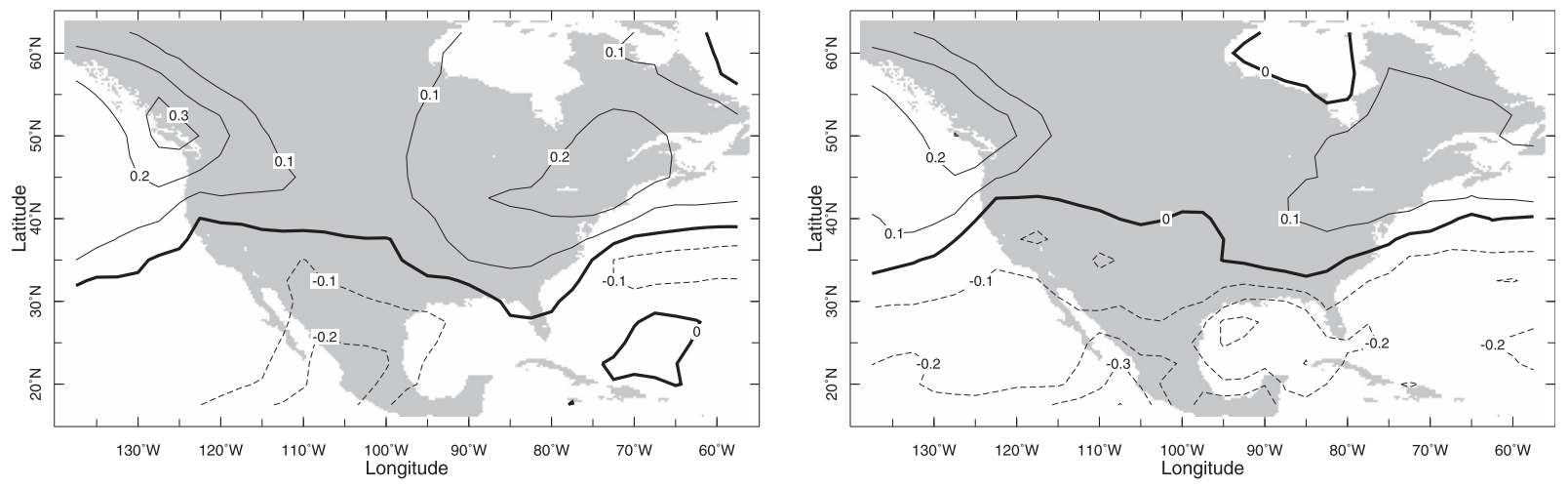

May-Oct
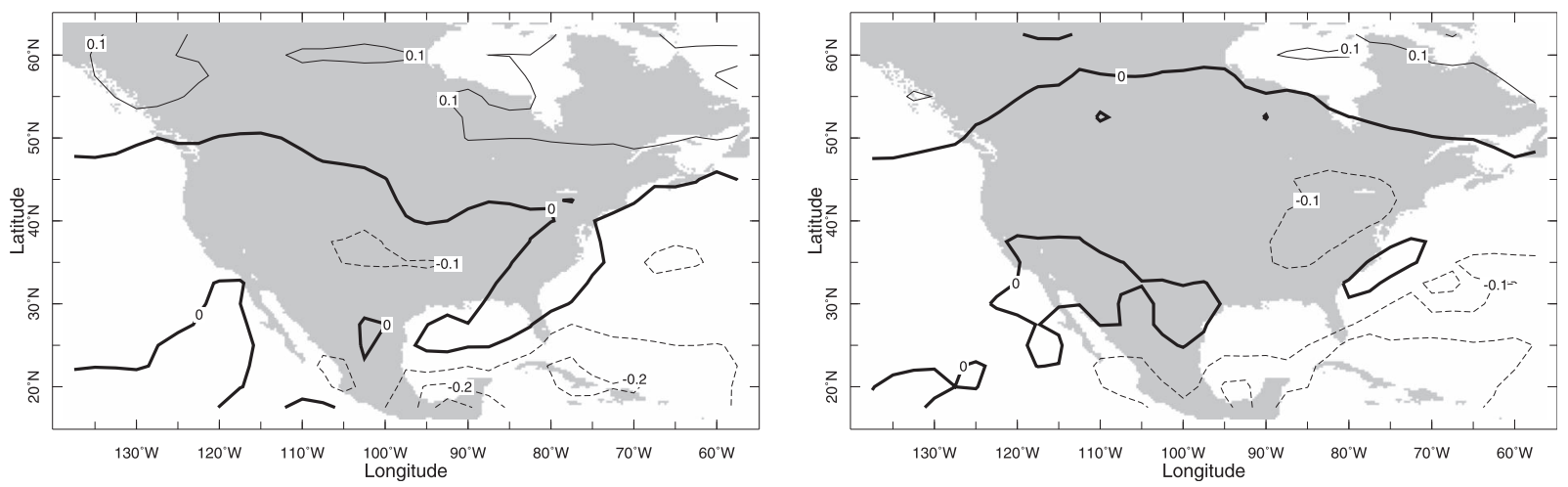

FIG. 15. The change (mm day ${ }^{-1}$ ) in (left) $P$ (left) and (right) $P-E$ for 2021-40 minus 1950-99 as projected by the ensemble mean of 24 IPCC AR4 models using the SRES A1B emissions scenario for the current century. Results are shown for the (top) winter and (bottom) summer half-years.

situation to the Southwest, where the projected reduction of $P-E$ is driven by a projected reduction of $P$ and $E$ reduces as the land surface dries (Seager et al. 2007b).

\section{Conclusions}

The recent 2-yr drought that struck the Southeast, by summer and fall 2007, had caused serious water shortages in the region, leading to the imposition of restrictions on water use and the opening up of legal conflicts within and between states on the regulation and use of the region's water resources. This is despite this 2-yr drought not being more severe than earlier droughts, including one as recently as 1998-2002, and indicates that the water shortage crisis was largely driven by rising demand.

Observed precipitation variations in the Southeast are weakly associated with ENSO during the winter halfyear, with La Niña leading to dry conditions, and are instead correlated to only internal atmospheric vari- ability in the summer half-year. A climate model forced by historical SSTs recreates the weak La Niña-dry Southeast link in the winter half-year but also creates this link, in a muted fashion, in the summer half-year. Apparently any such weak ENSO-preciptation link in the summer in observations is overwhelmed by internal atmospheric variability. The observed ENSO-winter precipitation link also varies in time being weak and of opposite sign from 1922 to 1950 , a feature that is not recreated by the model ensemble mean or by ensemble members.

All of this emphasizes the weakness of the ENSOSoutheast precipitation link, which is in contrast to a much stronger link for southwestern North America (see Seager et al. 2005a,b; Herweijer et al. 2006; Schubert et al. 2004a,b; Seager 2007; Seager et al. 2009. As a consequence, the time history of modeled and observed area-averaged Southeast precipitation is only weakly correlated in winter and not at all in summer. This weak temporal correlation was confirmed in five other climate 
model simulations. That there are multidecadal periods when the correlation between observed and modeled precipitation is higher (e.g., after 1950) might suggest some useful model skill, but this cannot be reliably exploited unless for some reason a temporally varying correlation, other than random chance, is discovered and the models can reproduce it. Overall, it appears that predictive skill of Southeast precipitation will be limited in winter and nonexistent in summer.

Despite the inability to usefully predict Southeast precipitation, it is important to assess the full character of precipitation variations in the Southeast. To do this we analyzed tree-ring reconstructions of PDSI for the period from A.D. 1000 to 2006. The tree-ring records show long periods of severe droughts that dwarf the turn-of-the-century drought in their persistence. One of these droughts seems to have occurred in 1555-74 and included 20 uninterrupted years of drought. This drought did not effect western North America. In contrast, the Southeast was also sometimes affected by the medieval megadroughts that were centered in western North America. Curiously, the early and mid-nineteenth century also appears as a long period of drier conditions after which the Southeast transitioned to a twentieth century that was noticeably wetter than the long-term mean of the millennium. The medieval droughts have been linked to persistent La Niña-like conditions in the tropical Pacific Ocean (Cobb et al. 2003; Herweijer et al. 2006; Cook et al. 2007; Graham et al. 2007; Seager et al. 2007a, 2008a), but the sixteenth and early- to midnineteenth-century droughts have not yet been attributed to any possible cause. Regardless, the tree-ring records clearly indicate that longer, and by that measure more severe, droughts have occurred in the Southeast than appear in the instrumental record of the twentieth century.

Turning to projections of anthropogenic climate change in the Southeast, models project that, in the near-future precipitation will increase year around in the Southeast north of southern Florida. However, precipitation minus evaporation $(P-E)$ decreases modestly in the annual mean, driven by increasingly negative $P-E$ in summer. This is in turn caused by an increase in evaporation, presumably related to atmospheric warming, that exceeds the increase in precipitation. Since $P-E$ is positive over land, this implies a weakening of moisture convergence by the atmospheric flow; however, we have not examined how this occurs. The reduction of $P-E$ is not robust in the sense that at any time up to a third of the models project an increase in $P-E$ while the remaining models projects a decrease.

To the extent that $P-E$ is reduced, the mechanism is different from that for the robust projection of reduced
$P-E$ in the Southwest, which is driven by reduced $P$, with $E$ reducing as soil moisture drops (Seager et al. 2007b). In the post-2005 drought, according to the NCEP reanalysis, $E$ dropped along with $P$, indicating that the recent drought was driven by a reduction of $P$ and not by an increase of $E$. Furthermore, the trends in $E$ for the 1949-2008 period computed from the NCEP reanalysis, and computed for the 1915-2003 period from the VIC land surface hydrology model, do not show an increase in $E$. These estimates of $E$ are likely to be quite uncertain, although the estimate from the VIC model is at least constrained by the observed precipitation, but they are consistent in showing no signature of projected anthropogenic climate change in the recent drought. That said, the projection of a modest reduction in the current century of $P-E$ by the model ensemble indicates that climate change should not be counted on to solve the Southeast's water woes and is, in fact, as likely to make matters worse as it is better.

Acknowledgments. This work was supported by NOAA Grants NA030AR4320179 (PO7 and 20A) and NSF Grants ATM-0347009 and ATM-0501878. AT was supported by an Earth Institute undergraduate fellowship. We thank Yochanan Kushnir, Mingfang Ting, Ed Cook, and Dave Stahle for their useful discussions; Cuihua Li and Naomi Naik for helping with the analysis of the IPCC simulations; and Naomi Naik for performing the CCM3 model simulations. We also thank the five reviewers and Andy Pitman (editor) for their useful criticisms of the submitted manuscript. The CCM3 model simulation data are available online (at http://kage.ldeo.columbia.edu:81/SOURCES/.LDEO/. ClimateGroup/.PROJECTS/.CCM3/).

\section{REFERENCES}

Allan, R. J., and T. J. Ansell, 2006: A new globally complete monthly historical mean sea level pressure dataset (HadSLP2): 18502004. J. Climate, 19, 5816-5842.

Alley, W. M., 1984: The Palmer drought severity index: Limitations and assumptions. J. Climate Appl. Meteor., 23, 1100-1109.

AMS Council, 1997: Policy statement: Meteorological drought. Bull. Amer. Meteor. Soc., 78, 847-849.

Andreadis, K. M., and D. P. Lettenmaier, 2006: Trends in 20th century drought over the continental United States. Geophys. Res. Lett., 33, L10403, doi:10.1029/2006GL025711.

Burke, E. J., S. J. Brown, and N. Christidis, 2006: Modeling the recent evolution of global drought and projections for the twenty-first century with the Hadley Centre climate model. J. Hydrometeor., 7, 1113-1125.

Cobb, K., C. D. Charles, H. Cheng, and R. L. Edwards, 2003: El Niño/Southern Oscillation and tropical Pacific climate during the last millennium. Nature, 424, 271-276.

Cocke, S., T. E. LaRow, and D. W. Shin, 2007: Seasonal rainfall predictions over the southeast United States using the Florida 
State University nested regional model. J. Geophys. Res., 112, D04106, doi:10.1029/2006JD007535.

Cole, J. E., and E. R. Cook, 1998: The changing relationship between ENSO variability and moisture balance in the continental United States. Geophys. Res. Lett., 25, 4529-4532.

Cook, E. R., and P. J. Krusic, 2004: North American summer PDSI reconstructions. IGBP PAGES/World Data Center for Paleoclimatology Data Contribution Series Tech. Rep. 2004-045, $24 \mathrm{pp}$.

, C. Woodhouse, C. M. Eakin, D. M. Meko, and D. W. Stahle, 2004: Long-term aridity changes in the western United States. Science, 306, 1015-1018.

—, R. Seager, M. A. Cane, and D. W. Stahle, 2007: North American droughts: Reconstructions, causes and consequences. Earth Sci. Rev., 81, 93-134.

Fye, F. K., D. W. Stahle, and E. R. Cook, 2003: Paleoclimatic analogs to twentieth-century moisture regimes across the United States. Bull. Amer. Meteor. Soc., 84, 901-909.

$\longrightarrow, \ldots$, and — 2004: Twentieth-century sea surface temperature patterns in the Pacific during decadal moisture regimes over the United States. Earth Interactions, 8. [Available online at http://EarthInteractions.org.]

Gershunov, A., and T. P. Barnett, 1998: Interdecadal modulation of ENSO teleconnections. Bull. Amer. Meteor. Soc., 79, 2715-2725.

— N N. Schneider, and T. P. Barnett, 2001: Low-frequency modulation of the ENSO-Indian monsoon rainfall relationship: Signal or noise? J. Climate, 14, 2486-2492.

Graham, N., and Coauthors, 2007: Tropical Pacific - mid-latitude teleconnections in medieval times. Climatic Change, 83, 241-285.

Heim, R. R., 2002: A review of twentieth-century drought indices used in the United States. Bull. Amer. Meteor. Soc., 83, 1149 1165.

Held, I. M., and B. J. Soden, 2006: Robust responses of the hydrological cycle to global warming. J. Climate, 19, 5686-5699.

Herweijer, C., R. Seager, and E. R. Cook, 2006: North American droughts of the mid to late nineteenth century: A history, simulation and implication for Mediaeval drought. Holocene, 16, 159-171.

- $-\longrightarrow$, , and J. Emile-Geay, 2007: North American droughts of the last millennium from a gridded network of tree-ring data. J. Climate, 20, 1353-1376.

Hoerling, M. P., and A. Kumar, 2003: The perfect ocean for drought. Science, 299, 691-694.

Houghton, J. T., G. J. Jenkins, and J. J. Ephraums, 2007: Climate Change: The IPCC Scientific Assessment. Cambridge University Press, $365 \mathrm{pp}$.

Huffman, G. J., and Coauthors, 1997: The Global Precipitation Climatology Project (GPCP) combined precipitation dataset. Bull. Amer. Meteor. Soc., 78, 5-20.

Kaplan, A., M. A. Cane, Y. Kushnir, A. C. Clement, M. B. Blumenthal, and B. Rajagopalan, 1998: Analyses of global sea surface temperature: 1856-1991. J. Geophys. Res., 103, 18 567-18 589.

Karl, T. R., 1986: The sensitivity of the Palmer drought severity index and Palmer's Z-index to their calibration coefficients including potential evapotranspiration. J. Climate Appl. Meteor., 25, 77-86.

Karnauskas, K. B., A. Ruiz-Barradas, S. Nigam, and A. J. Busalacchi, 2008: North American droughts in ERA-40 global and NCEP North American Regional Reanalyses: A Palmer drought severity index perspective. J. Climate, 21, 21022123.
Kiehl, J. T., J. J. Hack, G. B. Bonan, B. A. Boville, D. L. Williamson, and P. J. Rasch, 1998: The National Center for Atmospheric Research Community Climate Model: CCM3. J. Climate, 11, 1131-1149.

Kistler, R., and Coauthors, 2001: The NCEP-NCAR 50-Year Reanalysis: Monthly means CD-ROM and documentation. Bull. Amer. Meteor. Soc., 82, 247-267.

Kurtzman, D., and B. R. Scanlon, 2007: El Niño-Southern Oscillation and Pacific Decadal Oscillation impacts on precipitation in the southern and central United States: Evaluation of spatial distributions and predictions. Water Resour. Res., 43, W10427, doi:10.1029/2007WR005863.

Lau, N.-C., and M. J. Nath, 1994: A modeling study of the relative roles of tropical and extratropical SST anomalies in the variability of the global atmosphere-ocean system. J. Climate, 7, 1184-1207.

Liang, X., D. P. Lettenmaier, E. F. Wood, and S. J. Burges, 1994: A simple hydrologically based model of land surface water and energy fluxes for GCMs. J. Geophys. Res., 99, 14 415-14 428.

Mantua, N. J., S. R. Hare, Y. Zhang, J. M. Wallace, and R. C. Francis, 1997: A Pacific interdecadal climate oscillation with impacts on salmon production. Bull. Amer. Meteor. Soc., 78, 1069-1079.

Manuel, J., 2008: Drought in the Southeast: Lessons for Water Management. Environ. Health Perspect., 116, A168-A171.

McCabe, G. J., M. A. Palecki, and J. L. Betancourt, 2004: Pacific and Atlantic influences on multidecadal drought frequency in the United States. Proc. Natl. Acad. Sci. USA, 101, 4136-4141.

Milly, P. C. D., K. A. Dunne, and A. V. Vecchia, 2005: Globa pattern of trends in streamflow and water availability in a changing climate. Nature, 438, 347-350.

Palmer, W. C., 1965: Meteorological drought. U.S. Weather Bureau Research Paper 45, 58 pp.

Rayner, N., D. Parker, E. Horton, C. Folland, L. Alexander, D. Rowell, E. Kent, and A. Kaplan, 2003: Global analyses of sea surface temperature, sea ice, and night marine air temperature since the late nineteenth century. J. Geophys. Res., 108, 4407, doi:10.1029/2002JD002670.

Ropelewski, C. F., and M. S. Halpert, 1986: North American precipitation and temperature patterns associated with the El Niño/Southern Oscillation (ENSO). Mon. Wea. Rev., 114, 2352-2362.

— terns associated with the El Niño/Southern Oscillation. Mon. Wea. Rev., 115, 1606-1626.

— high index phase of the Southern Oscillation. J. Climate, 2, 268-284.

—, and — 1996: Quantifying Southern Oscillation-precipitation relationships. J. Climate, 9, 1043-1059.

Schubert, S. D., M. J. Suarez, P. J. Pegion, R. D. Koster, and J. T. Bacmeister, 2004a: Causes of long-term drought in the United States Great Plains. J. Climate, 17, 485-503.

,,,----1, and,$- 2004 \mathrm{~b}$ : On the cause of the 1930s Dust Bowl. Science, 303, 1855-1859.

Seager, R., 2007: The turn of the century North American drought: Global context, dynamics, and past analogs. J. Climate, 20, 5527-5552.

_ , N. Harnik, Y. Kushnir, W. Robinson, and J. Miller, 2003: Mechanisms of hemispherically symmetric climate variability. J. Climate, 16, 2960-2978.

$\longrightarrow,-$ W W. A. Robinson, Y. Kushnir, M. Ting, H. P. Huang, and J. Velez, 2005a: Mechanisms of ENSO-forcing of hemispherically 
symmetric precipitation variability. Quart. J. Roy. Meteor. Soc., 131, 1501-1527.

Y. Kushnir, C. Herweijer, N. Naik, and J. Velez, 2005b Modeling of tropical forcing of persistent droughts and pluvials over western North America: 1856-2000. J. Climate, 18, 4068-4091.

—, N. Graham, C. Herweijer, A. Gordon, Y. Kushnir, and E. R. Cook, 2007a: Blueprints for Medieval hydroclimate. Quat. Sci. Rev., 26, 2322-2336.

— , and Coauthors, 2007b: Model projections of an imminent transition to a more arid climate in southwestern North America. Science, 316, 1181-1184.

—, R. Burgman, Y. Kushnir, A. C. Clement, E. R. Cook, N. Naik, and J. Miller, 2008a: Tropical Pacific forcing of North American medieval megadroughts: Testing the concept with an atmosphere model forced by coral-reconstructed SSTs. J. Climate, 21, 6175-6190.

_- Y. Kushnir, M. Ting, M. A. Cane, N. Naik, and J. Velez, 2008b: Would advance knowledge of 1930s SSTs have allowed prediction of the Dust Bowl drought? J. Climate, 21, 32613281.
— , and Coauthors, 2009: Mexican drought: An observational modeling and tree ring study of variability and climate change. Atmósfera, 22, 1-31.

Stahle, D. W., E. R. Cook, M. K. Cleaveland, M. D. Therrell, D. Meko, H. Grissino-Mayer, E. Watson, and B. H. Luckman, 2000: Tree-ring data document 16th century megadrought over North America. EOS, Trans. Amer. Geophys. Union, 81, 121.

—, F. K. Fye, E. R. Cook, and R. D. Griffin, 2007: Tree-ring reconstructed megadroughts over North America since A.D. 1300. Climatic Change, 83, 133-149.

Tootle, G. A., and T. C. Piechota, 2006: Relationships between Pacific and Atlantic ocean sea surface temperatures and U.S. streamflow variability. Water Resour. Res., 42, W07411, doi:10.1029/2005WR004184.

van der Schrier, G., K. R. Briffa, T. J. Osborn, and E. R. Cook, 2006: Summer moisture variability across North America. J. Geophys. Res., 111, D11102, doi:10.1029/2005JD006745.

Wu, A., W. W. Hsieh, and A. Shabbar, 2005: The nonlinear patterns of North American winter temperature and precipitation associated with ENSO. J. Climate, 18, 1736-1752. 